UNIVERSIDADE DE SÃO PAULO

ESCOLA DE ENFERMAGEM

HELOISA RIBEIRO DO NASCIMENTO

AUTOCUIDADO EM INSUFICIÊNCIA CARDÍACA:
ESTUDO COMPARATIVO ENTRE PACIENTES DE
CLÍNICA ESPECIALIZADA E PRONTO-SOCORRO

SÃO PAULO

2012 
HELOISA RIBEIRO DO NASCIMENTO

\section{AUTOCUIDADO EM INSUFICIÊNCIA CARDÍACA: ESTUDO COMPARATIVO ENTRE PACIENTES DE CLÍNICA ESPECIALIZADA E PRONTO-SOCORRO}

Dissertação apresentada ao Programa de Pós-Graduação em Enfermagem na Saúde do Adulto da Escola de Enfermagem da Universidade de São Paulo para obtenção do título de Mestre em Enfermagem.

Orientadora:

Prof ${ }^{a}$. Dra ${ }^{\mathrm{a}}$. Vilanice Alves de Araújo Püschel 
AUTORIZO A REPRODUÇÃO E DIVULGAÇÃO TOTAL OU PARCIAL DESTE TRABALHO, POR QUALQUER MEIO CONVENCIONAL OU ELETRÔNICO, PARA FINS DE ESTUDO E PESQUISA, DESDE QUE CITADA A FONTE.

Assinatura:

Data:

\author{
Catalogação na Publicação (CIP) \\ Biblioteca "Wanda de Aguiar Horta" \\ Escola de Enfermagem da Universidade de São Paulo
}

Nascimento, Heloisa Ribeiro do

Autocuidado em insuficiência cardíaca: estudo

comparativo entre pacientes de clínica especializada e

pronto-socorro / Heloisa Ribeiro do Nascimento - São Paulo, 2012.

115 p. : Il.

Dissertação (Mestrado) - Escola de Enfermagem da Universidade de São Paulo.

Orientadora: $\operatorname{Prof}^{\mathrm{a}} \mathrm{Dr}^{\mathrm{a}}$ Vilanice Alves de Araujo Püschel

Área de concentração: Saúde do adulto

1. Insuficiência cardíaca 2. Autocuidado 3. Enfermagem I. Título. 
NOME: HELOISA RIBEIRO DO NASCIMENTO

TÍTULO: AUTOCUIDADO EM INSUFICIÊNCIA CARDÍACA: ESTUDO COMPARATIVO ENTRE PACIENTES DE CLÍNICA ESPECIALIZADA E PRONTO- SOCORRO

Dissertação apresentada ao Programa de Pós-Graduação em Enfermagem na Saúde do Adulto da Escola de Enfermagem da Universidade de São Paulo, para obtenção do título de Mestre em Enfermagem na Saúde do Adulto.

Aprovada em:

\section{Banca Examinadora}

Prof. Dr.

Instituição:

Julgamento:

Assinatura:

Prof. Dr.

Instituição:

Julgamento:

Assinatura:

Prof. Dr.

Instituição:

Julgamento:

Assinatura:

Prof. Dr.

Instituição:

Julgamento:

Assinatura: 


\section{Dedícatóría}

Aos meus país Ladislau e María Aparecída:

Pelos ensinamentos de toda a vida e pelo exemplo de caráter, honestidade e humildade.

Pela confíança e estímulo desde a infância, víbrando com cada conquista, incansavelmente.

Pela oportunidade de estar aqui e poder dedicarThes este trabalho. 
$\mathcal{A}$ Deus,

"Que darei eu ao Senhor por todos os benefícios que me tem feito?" (Salmos 116. 12) 


\section{Agradecimentos}

À minha orientadora, Professora Doutora Vílanice Alves de Araújo Püschel, pela paciência e competência, que tornaram possiveis a conclusão deste estudo. Por proporcionar este periodo de aprendizado e crescimento pessoal e profissional.

Ao Professor Doutor Edimar Alcides Bocchí e Dra Fátima das Dores da Cruz pela receptividade, disponibilidade e contribuição para a realização deste estudo.

Aos enfermeiros do Instituto do Coração, pela colaboração e apoio, especíalmente à equípe do ambulatório, pela receptividade e paciêncía.

Às professoras e colegas da Escola de Enfermagem da Universidade de São Paulo, por tornar o ambiente tão acolhedor e estimulante para a construção do conhecimento.

Ao profissional de estatística da Escola de Enfermagem, Lucas Petri Damiani, pela paciência e disponibilidade.

Aos pacientes da Unidade Clínica de Insufíciência Cardíaca e Pronto-Socorro, pelo consentimento em participar deste estudo e pelas valiosas experiências compartilhadas durante as entrevistas.

Aos colegas do Hospital Sírío Líbanês, que me incentivaram e apoiaram durante este periodo.

Aos amigos, que sempre acreditaram e me deram palavras de estimulo em momentos dificeis.

À minha família, pela paciência, compreensão e auxílio, respeitando minha distância e sacrificando suas atividades para tornar o ambiente propicio para o estudo. 
"Suba o primeíro degrau com fé. Não é necessárío que você veja toda a escada. Apenas dê o primeíro passo."

Martin Luther King 
Nascimento HR. Autocuidado em Insuficiência Cardíaca: Estudo comparativo entre pacientes de clínica especializada e Pronto-Socorro [dissertação] São Paulo: Escola de Enfermagem, Universidade de São Paulo; 2012.

\section{RESUMO}

Trata-se de um estudo descritivo correlacional com abordagem quantitativa, que teve como objetivos: caracterizar pacientes com Insuficiência Cardíaca (IC) atendidos em clínica especializada (grupo A) e em pronto-socorro (grupo B), conforme perfil sócio-demográfico, perfil clínico, tempo de conhecimento da doença e internações no último ano; Identificar ações de autocuidado específicas nos grupos A e B; Verificar a diferença entre o autocuidado dos grupos A e B e Identificar os possíveis fatores precipitantes de descompensação no grupo B. A amostra foi constituída por 120 pacientes de um hospital especializado em cardiologia, localizado no município de São Paulo, sendo 60 em cada grupo. A coleta de dados foi realizada de julho a novembro de 2011, por meio da aplicação de instrumento elaborado para o estudo (1) e instrumento de adesão validado em estudo prévio (2). A análise estatística foi descritiva e inferencial, sendo utilizado o Alpha de Cronbach para avaliar a consistência interna do instrumento 2, Teste Exato de Fisher para variáveis categóricas, Teste t-student para comparação entre as médias das variáveis contínuas, teste não paramétrico de Mann-Whitney quando se rejeitou a hipótese de normalidade da variável. Predominou o sexo masculino $78(65 \%)$. Não houve diferença no tempo de conhecimento da doença entre os grupos. Observou-se que o grupo B teve mais internações no último ano. Não houve diferença estatisticamente significativa no escore de adesão do Instrumento 2, com média $46,09( \pm 8,03)$ entre os grupos, para um escore máximo $=60$. Observou-se pior resultado nas ações de autocuidado referentes à percepção de piora clínica e comunicação com a equipe de saúde; controle de peso e vacinação contra influenza, sem diferença significativa entre os grupos. Identificou-se maior número de idosos, aposentados, sem renda e residindo sozinhos; chagásicos, com piores níveis de uréia, creatinina e hemoglobina e em uso de marcapasso no grupo B. No perfil hemodinâmico do grupo B, verificou-se que $44(73,4 \%)$ pacientes apresentaram sinais de congestão e $37(61,7 \%)$ sinais de baixo débito cardíaco, o que contribuiu para internação prolongada e alta letalidade. Conclui-se que os pacientes realizam parcialmente as ações de autocuidado, devido à dificuldade na percepção e comunicação da piora clínica; controle de peso e vacinação contra influenza, sem diferença significativa entre os grupos. Os possíveis fatores precipitantes de descompensação no grupo $B$ relacionam-se à idade avançada, condições sócio-econômicas e pior perfil clínico. A continuidade deste estudo, com seguimento em seis meses, permitirá identificar os principais desfechos a curto prazo. Sugere-se o acompanhamento de pacientes em ambiente familiar para avaliar a real situação dos cuidados e o desenvolvimento de estudos voltados ao autocuidado de pessoas com IC avançada e/ou de etiologia chagásica, incluindo a criação de programas de cuidados paliativos.

Palavras-Chave: Insuficiência Cardíaca. Autocuidado. Enfermagem. 


\begin{abstract}
This is a descriptive and correlational study with a quantitative approach, that aimed to characterize patients with heart failure (HF) treated in a Specialty Clinic (Group A) and Emergency Room (Group B), according to socio-demographic and clinical profiles, knowledge time of the disease and hospitalizations in the previous year; Identify specific actions of self-care specifically in Groups A and B; Check the difference between self-care in Groups A and B and identify the possible precipitating factors of decompensation in Group B. The sample consisted of 120 patients in a São Paulo, hospital specialized in cardiology, with 60 patients in each group. Data collection was conducted from July to November 2011, by applying an instrument developed for this study (1) and an instrument of accession validated in a previous study (2). Statistical analysis was descriptive and inferential, by using Cronbach's alpha to assess internal consistency of instrument 2, Fisher's Exact Test for categorical variables, Student's t-test for comparison between means of continuous variables, and non-parametric Mann-Whitney when it rejected the hypothesis of normality of the variable. Seventy-eight (78) males or $65 \%$ predominated in this study. There was no difference in the knowledge time of the disease between the groups however it was observed that Group B had more hospitalizations in the past year. There was no statistically significant difference in adherence score of Instrument 2, averaging 46.09 ( \pm 8.03) between the groups, for a maximum score $=60$. Worse results were observed in the actions of self-care with reference to the perception of clinical worsening and communication with the health team; weight control and influenza vaccination, without a significant difference between the groups. It was identified that the greater number of elderly, retired, no income and living alone; chagasic patients having worse levels of urea, creatine and hemoglobin and pacemaker use were all in Group B. In the hemodynamic profile of Group B, it was found that 44 (73.4\%) patients showed signs of congestion and $37(61.7 \%)$ signs of low cardiac output, contributing to prolonged hospitalization and high mortality. It was concluded that patients perform self-care actions in part because of the difficulty in perception and communication of clinical worsening, weight control and influenza vaccination, without significant difference between the groups. Possible precipitating factors of decompensation in Group B are related to advanced age, socio-economic status and worse clinical profiles. The continuity of this study, with a follow-up in six months, will identify the principal outcomes in the short term. It is suggested that the monitoring of patients be done in a family environment to assess the real situation of care and the development of studies to self-care of people with advanced HF and / or Chagas disease, including the establishment of palliative care programs.
\end{abstract}

Key Words: Heart Failure. Self-care. Nursing. 


\section{LISTA DE TABELAS}

Tabela 1 -

Tabela 2 -

Tabela 3 -

Tabela 4 -

Tabela 5 -

Tabela 6 -

Tabela 7 -

Tabela 8 -

Tabela 9 -

Tabela 10 -

Tabela 11 -

Tabela 12 -

Tabela 13 -

Tabela 14 -

Tabela 15 -

Tabela 16 -
Perfil sócio-demográfico dos pacientes com Insuficiência

Cardíaca, Incor, São Paulo - 2011.

Etiologia da Insuficiência Cardíaca, Incor, São Paulo - 2011

Doenças associadas em pacientes com Insuficiência

Cardíaca, Incor, São Paulo - 2011

Medicamentos usados por pacientes com Insuficiência

Cardíaca, Incor, São Paulo - 2011

Classe funcional conforme classificação da "New York Heart

Association" (NYHA) em pacientes com Insuficiência

Cardíaca, Incor, São Paulo - 2011

Valores de fração de ejeção, diâmetro sistólico e diâmetro

diastólico dos pacientes com Insuficiência Cardíaca, Incor,

São Paulo - 2011

Valores de exames laboratoriais dos pacientes com

Insuficiência Cardíaca, Incor, São Paulo - 2011

Ocorrência de internações não planejadas no último ano em pacientes com Insuficiência Cardíaca, Incor, São Paulo - 2011

Ocorrência de internações não planejadas no último ano de acordo com a etiologia em pacientes com Insuficiência Cardíaca, Incor, São Paulo - 2011.

Hábitos sobre o controle de peso em pacientes com Insuficiência Cardíaca, Incor, São Paulo - 2011

Percepção do aumento de peso e procura pela equipe de saúde em pacientes com Insuficiência Cardíaca, Incor, São Paulo - 2011

Percepção da falta de ar e procura pela equipe de saúde em pacientes com Insuficiência Cardíaca, Incor, São Paulo - 2011 .......70

Percepção do edema periférico e procura pela equipe de saúde em pacientes com Insuficiência Cardíaca, Incor, São Paulo - 2011

Vacinação anual contra influenza em pacientes com Insuficiência Cardíaca, Incor, São Paulo - 2011

Orientação sobre restrição de líquidos e controle de peso diário em pacientes com Insuficiência Cardíaca, Incor, São Paulo - 2011

Escore por questão do "Questionário de Aderência em pacientes com Insuficiência Cardíaca”, Incor, São Paulo 2011 
Tabela 17 -

Tabela 18 -

Tabela 19 -
Perfil hemodinâmico em pacientes com Insuficiência Cardíaca descompensada, Incor, São Paulo - 2011..

Avaliação e tratamento em pacientes com Insuficiência Cardíaca descompensada, Incor, São Paulo - 2011 77

Principais desfechos em pacientes com Insuficiência Cardíaca descompensada, internados no pronto-socorro. Incor,São Paulo - 2011 


\section{LISTA DE FIGURAS}

Figura 1 - $\quad$ FEVE por Etiologia em pacientes com Insuficiência Cardíaca, Incor, São Paulo - 2011.

Figura 2 - $\quad$ Tempo de conhecimento sobre a doença por grupo e associação com ocorrência de internação no último ano em pacientes com Insuficiência Cardíaca, Incor, São Paulo 2011. .66

Figura 3 - $\quad$ Escore total do "Questionário de Aderência em pacientes com Insuficiência Cardíaca", Incor, São Paulo - 2011 ..................................74 


\section{LISTA DE SIGLAS}

\begin{tabular}{ll} 
ATC & - Angioplastia Transluminal Coronariana \\
BNP & - Peptídeo natriurético do tipo B \\
BRA & - Bloqueadores dos receptores de angiotensina II \\
DAC & - Doença arterial coronariana \\
DCV & - Doença cérebro vascular \\
DM & - Diabetes mellitus \\
ECG & - Eletrocardiograma \\
ECO & - Ecocardiograma \\
EUA & - Estados Unidos da América \\
FEVE & - Fração de ejeção do Ventrículo Esquerdo \\
HAS & - Hipertensão arterial sistêmica \\
HC & - Hospital das Clínicas \\
IC & - Insuficiência cardíaca \\
ICD & - Insuficiência cardíaca descompensada \\
INCOR & - Instituto do Coração \\
IAM & - Infarto agudo do miocárdio \\
IECA & - Inibidores da enzima conversora de angiotensina \\
MPD & - Marcapasso definitivo \\
NYHA & - New York Heart Association \\
OMS & - Organização Mundial de Saúde \\
QRVS & - Qualidade de vida relacionada à saúde \\
RM & - Revascularização do miocárdio \\
SUS & - Sistema Único de Saúde \\
TSH & - Hormônio estimulante de tireoide \\
USP & - Universidade de São Paulo \\
VE & - Ventrículo esquerdo \\
\hline IN &
\end{tabular}




\section{SUMÁRIO}

2 REVISÃO DE LITERATURA

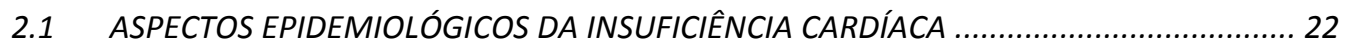

2.1.1 Aspectos epidemiológicos de acordo com a etiologia da Insuficiência Cardíaca 24

2.2 DIRETRIZES NO DIAGNÓSTICO E TRATAMENTO DA INSUFICIÊNCIA CARDÍACA

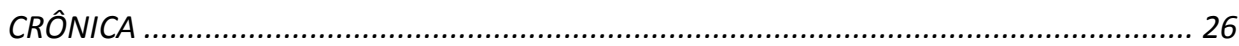

2.3 DIRETRIZES NO DIAGNÓSTICO E TRATAMENTO DA INSUFICIÊNCIA CARDÍACA

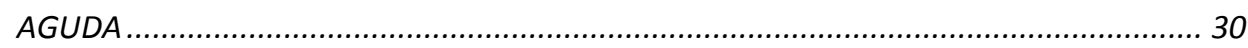

2.4 A ADESÃO AO TRATAMENTO E O AUTOCUIDADO COMO FOCO DAS AÇÕES

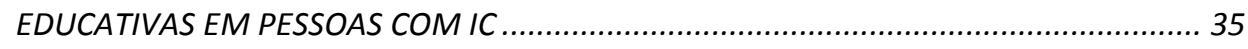

2.4.1 Conceitos de adesão ao tratamento e autocuidado .......................................... 35

2.4.2 Ações educativas voltadas para o autocuidado e adesão ao tratamento da IC. 38

4 METODOLOGIA .49

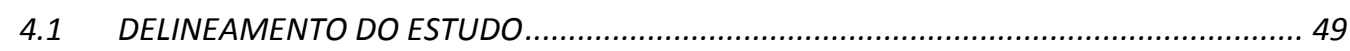

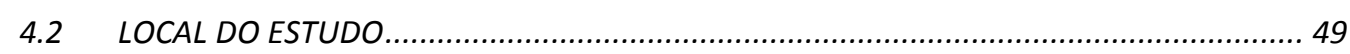

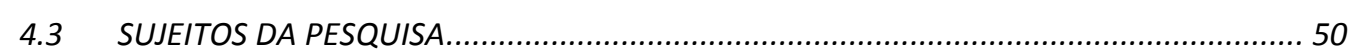

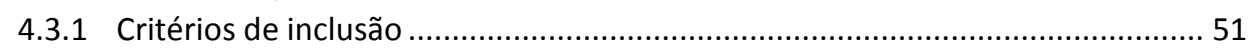

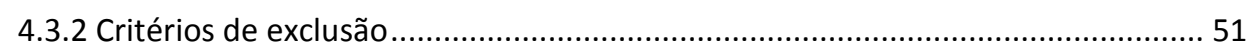

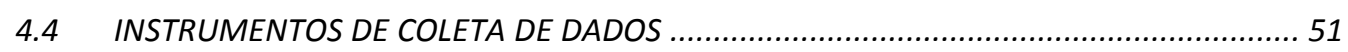

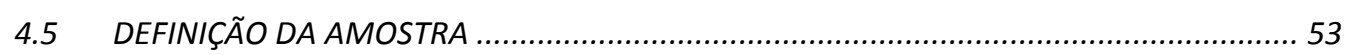

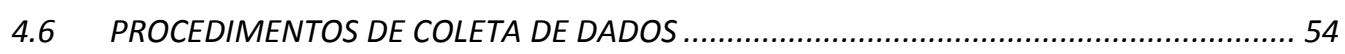

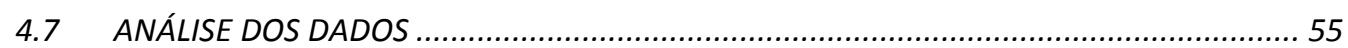

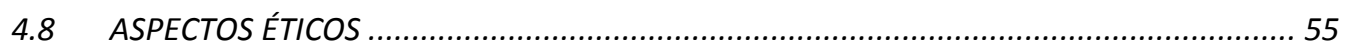

$5 \quad$ RESULTADOS

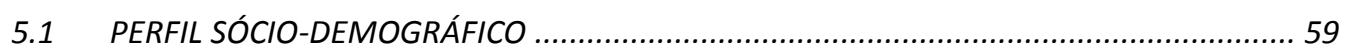

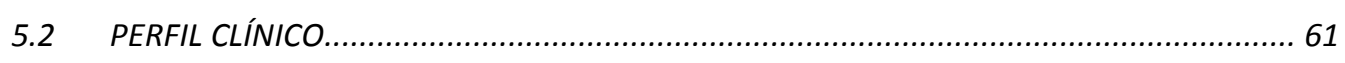

5.3 TEMPO DE CONHECIMENTO SOBRE A DOENÇA E INTERNAÇÕES NO ÚLTIMO ANO.

5.4 AÇÕES DE AUTOCUIDADO ESPECÍFICAS EM PESSOAS COM INSUFICIÊNCIA CARDÍACA EM CLÍNICA ESPECIALIZADA E PRONTO-SOCORRO …............................... 67

5.4.1 Adesão ao tratamento em pacientes com Insuficiência Cardíaca....................... 73

5.5 PERFIL DE PACIENTES COM INSUFICIÊNCIA CARDÍACA DESCOMPENSADA ................... 76

6 DISCUSSÃO

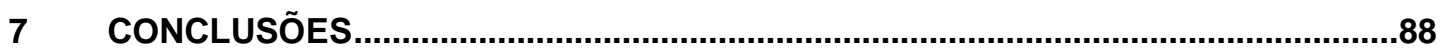

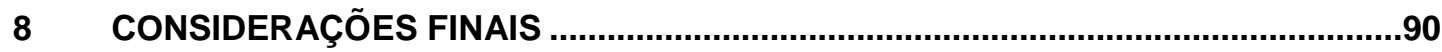

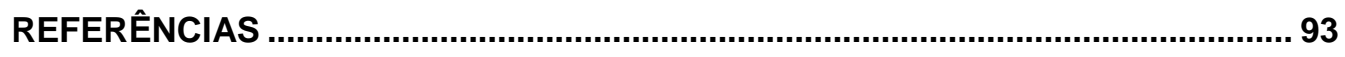

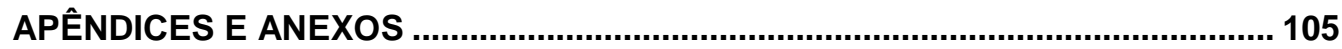




\section{APRESENTAÇÃO}

Em 2006, iniciei minhas atividades como enfermeira assistencial em uma unidade de terapia semi-intensiva cardiológica, onde presenciei diversas situações clínicas complexas, as quais exigiam cuidados específicos por parte da equipe multiprofissional.

Após um período de dois anos de trabalho, passei a observar as características específicas de algumas afecções, em especial, da insuficiência cardíaca (IC), devido aos diversos episódios de readmissões hospitalares dos pacientes.

Durante as abordagens que fazia aos pacientes, ouvia os relatos sobre a dificuldade em cumprir o regime terapêutico e muitas vezes, afirmações de que retornavam ao hospital embora cumprissem as orientações de seus médicos. Dessa forma, passei a me inquietar com as questões envolvidas no tratamento da IC, principalmente as questões relacionadas à participação do paciente no complexo regime terapêutico. Neste contexto, surgiu o interesse em realizar um estudo para investigar o autocuidado de pacientes com IC. 


\section{Introdução}




\section{INTRODUÇÃO}

A IC é uma síndrome clínica complexa de caráter sistêmico, definida como uma disfunção cardíaca que ocasiona inadequado suprimento sanguíneo para atender as necessidades metabólicas tissulares, na presença de retorno venoso normal, ou fazê-lo somente com elevadas pressões de enchimento ${ }^{1}$.

É caracterizada por sintomas severos, como a dispneia, edema e intolerância progressiva aos esforços, além de provocar impacto físico, psicológico e social aos pacientes com IC, devido à diminuição funcional e perda da qualidade de vida nas atividades diárias ${ }^{2}$.

Trata-se de um problema de saúde pública devido à elevada incidência e altas taxas de mortalidade. Embora tenha havido progresso no tratamento, a IC permanece como uma das principais causas de hospitalização em vários países, incluindo o Brasil e está associada a elevadas taxas de morbidade e mortalidade, custos para o sistema de saúde e piora na qualidade de vida dos pacientes.

A IC descompensada (ICD) é a apresentação frequente da IC, resultando em grande número de internações. Em geral, uma das principais causas da ICD é o inadequado controle da IC devido à dificuldade dos pacientes em aderir ao complexo regime terapêutico e em tomar atitudes adequadas diante da piora clínica.

As várias abordagens ao cuidado da IC, investigadas em estudos clínicos, tem aumentado a complexidade do tratamento. Diante disso, diferentes estratégias de enfermagem baseadas na educação e no seguimento intensivo de pacientes com IC têm sido empregadas. 
Diversos estudos vêm sendo realizados, a fim de elucidar as dificuldades enfrentadas pelas pessoas com IC no cumprimento do tratamento proposto e propor caminhos para o melhor manejo e desfecho clínico.

Em 1988, foi publicado o primeiro estudo que avaliou os fatores precipitantes de descompensação clínica em pacientes com IC. Os resultados mostraram que potenciais fatores estavam presentes em $93 \%$ dos pacientes. A falta de adesão ao regime prescrito pelo médico foi identificada em $64 \%$, o descumprimento da dieta em $22 \%$ e do tratamento farmacológico em $6 \%$. Sendo que em $37 \%$ dos pacientes foi identificada falta de adesão ao tratamento farmacológico e dieta. Estes resultados demonstraram a dificuldade dos pacientes em aderir ao tratamento, especialmente o não farmacológico e sugeriram a realização de estudos com propostas de educação como uma forma de evitar internações, reduzir custos e reduzir o sofrimento dos pacientes com $\mathrm{IC}^{3}$.

Estudos realizados posteriormente não demonstraram modificação no perfil dos pacientes com IC, reafirmando que a complexidade do regime terapêutico supõe um importante desafio para os profissionais de saúde, uma vez que existem numerosas lacunas e ineficiências no manuseio desses pacientes, evidenciado pelos elevados índices de readmissões hospitalares, causadas principalmente pela dificuldade dos pacientes em praticar o autocuidado e aderir ao tratamento ${ }^{4-10}$.

Nesse cenário, o trabalho e pesquisa multidisciplinar passaram a ser aceitos e divulgados, já que estudos comprovaram sua eficácia, destacando o papel do enfermeiro principalmente como educador sobre medidas não farmacológicas, importantes na redução de internações e na melhora da qualidade de vida dos pacientes com $\mathrm{IC}^{3,10,11,12}$.

Assim, o autocuidado passou a ser considerado um aspecto importante do tratamento, pois a maioria dos programas de atenção à IC enfatizou que o autocuidado poderia ser a chave para a obtenção de uma 
melhor evolução dos pacientes. Portanto, que a educação em saúde sobre questões relativas à doença e tratamento poderia influenciar as atitudes dos pacientes com IC, melhorar a adesão ao tratamento, reduzir internações, tempo de internação, custo do tratamento e mortalidade, além de contribuir para a melhora na qualidade de vida ${ }^{10,11}$. Além disso, passou-se a acreditar que a educação sistemática de enfermagem associada a outras estratégias, aumentaria o conhecimento sobre a doença e o autocuidado, podendo contribuir na redução de episódios de descompensação e consequentemente, melhorar a qualidade de vida em pessoas com IC ${ }^{13}$.

O reconhecimento da importância da educação em pacientes com IC reforçou o conceito de programa de aconselhamento ou programa de manejo, amplamente empregado nos dias de hoje. No entanto, ainda existem lacunas sobre os mecanismos envolvidos na melhora dos resultados, sobre a melhor forma de abordagem educacional e sobre o tipo de paciente que possa se beneficiar com estas abordagens.

Pesquisadores afirmam que pouco se sabe sobre os mecanismos que explicam a melhora dos resultados aos programas educativos e sugerem a realização de estudos direcionados à melhora do conhecimento acerca do autocuidado e do cumprimento do regime terapêutico ${ }^{14}$.

Este estudo teve o intuito de avaliar o autocuidado específico em pacientes com IC, a partir de um instrumento validado; identificar possíveis fatores precipitantes de descompensação, perfil de pacientes que poderiam se beneficiar de programas de manejo, além de indicar possíveis mudanças nestes programas baseadas nas necessidades educativas dos pacientes. 
Revísão de Literatura 


\section{REVISÃO DE LITERATURA}

\subsection{ASPECTOS EPIDEMIOLÓGICOS DA INSUFICIÊNCIA CARDÍACA}

A IC é a síndrome crônica mais comum entre os idosos nos países desenvolvidos. Somente nos Estados Unidos da América (EUA), a prevalência da IC é de 5.700.000, com incidência de 550 mil por ano e mortalidade de 300 mil pacientes por ano, representando uma em cada oito mortes $^{15}$.

O aumento da expectativa de vida nos países desenvolvidos tem influenciado a epidemiologia da IC. Estima-se que aproximadamente 23 milhões de pessoas tenham IC e que dois milhões de novos casos de IC sejam diagnosticados a cada ano no mundo ${ }^{16}$. Cerca de 6,5 milhões de pessoas na Europa, cinco milhões de pessoas nos Estados Unidos, e 2,4 milhões de pessoas no Japão sofrem de $I^{15}$.

Uma revisão sistemática de estudos recentes sobre a epidemiologia da IC, realizada na Austrália, trouxe questionamentos sobre a suposta "epidemia" defendida por diversos autores nos últimos anos, visto que os estudos revisados evidenciaram declínio na mortalidade por IC e a falta de relatórios que mostrassem o aumento na incidência da IC no período de 1995 a 2005. No entanto, os relatórios sobre as tendências na sobrevivência das pessoas com IC, juntamente com o expansivo envelhecimento da população, sugeriram o aumento da incidência de IC no futuro ${ }^{17}$.

Nos países em desenvolvimento, a epidemiologia é cada vez mais semelhante à dos países desenvolvidos, visto que aumentou a prevalência da IC, graças ao controle das doenças transmissíveis e desnutrição e ao envelhecimento da população, além da contribuição de doenças como hipertensão e doença isquêmica do coração ${ }^{18}$. No Brasil, a IC já se tornou a 
primeira causa de internação hospitalar em pacientes acima de 60 anos de idade e a sexta causa de internação em pacientes entre 15 e 59 anos ${ }^{19}$.

No Brasil, não estão disponíveis estudos epidemiológicos envolvendo a incidência de IC. Porém estima-se que 6,4 milhões de brasileiros sofram de $\mathrm{IC}^{15}$.

Em 2006, os dados do Sistema Único de Saúde (SUS) mostravam que a evolução dos pacientes com IC não vinha se modificando muito, tanto em relação à mortalidade hospitalar quanto em relação ao número de pacientes hospitalizados a cada ano. Os dados epidemiológicos indicavam que a incidência de insuficiência cardíaca estava aumentando progressivamente, sobretudo em idosos ${ }^{20}$.

No período de 2000 a 2007, os gastos decorrentes de hospitalizações por IC no SUS tiveram aumento de $11,3 \%$ e de $64,7 \%$ nos gastos unitários por internação. Em 2006, a IC e cardiopatias associadas à IC foram responsáveis por 6,3\% dos óbitos no Estado de São Paulo, estado mais populoso do Brasil com 41.654.020 habitantes. Em 2006 e 2007 a IC foi responsável por $2,6 \%$ das hospitalizações e por $6 \%$ dos óbitos registrados pelo SUS no Brasil, consumindo 3\% do total de recursos utilizados para atender todas as internações ${ }^{1}$.

Estudo prospectivo histórico no município de São Paulo, de 1992 a 2010, mostrou que houve redução de $32 \%$ no número de internações entre 1992 e 1993 comparado a 2008 e 2009. No entanto, a taxa de mortalidade hospitalar por IC foi de $15 \%$, com aumento de $15 \%$ no segundo período e o tempo de hospitalização aumentou 25\%, de 8,8 dias entre 1992 e 1993 para 11,3 dias entre 2008 e $2009^{21}$. Esses dados nos fornecem um cenário sombrio e de grande preocupação, pois houve aumento na taxa de mortalidade concomitantemente à redução de hospitalizações, mostrando que os pacientes devem ser mais graves, há falta de vagas, o tratamento utilizado não está sendo eficaz e provavelmente a IC está sendo substituída por patologias menos onerosas aos hospitais ${ }^{22}$. 


\subsubsection{Aspectos epidemiológicos de acordo com a etiologia da Insuficiência Cardíaca}

A definição da etiologia faz parte da avaliação inicial do paciente com IC, logo após a identificação de sinais e sintomas. A IC pode ser classificada como chagásica, hipertensiva, miocardite, isquêmica, alcoólica e idiopática, a partir dos seguintes critérios:

- Chagásica: Antecedente epidemiológico, sorologia positiva para Chagas, eletrocardiograma (ECG) com bloqueio de ramo direito (BRD) ou bloqueio divisional anterossuperior (BDAS), ecocardiograma (ECO) com aneurisma apical;

- Hipertensiva: história de hipertensão arterial sistêmica (HAS), exclusão de outras etiologias;

- Miocardite: História recente de infecção viral, IC de início recente (<2 meses), exclusão de outras etiologias;

- Isquêmica: Fatores de risco para doença arterial coronariana (DAC), história de infarto agudo do miocárdio (IAM), revascularização do miocárdio $(\mathrm{RM})$ e angioplastia transluminal coronariana (ATC), ECG com área inativa (AEI) ou sinais isquemia miocárdica, ECO com alteração de contração segmentar ou presença de aneurisma apical;

- Alcoólica: História de ingestão maior que $90 \mathrm{~g} / \mathrm{dia}$ de álcool (8 doses) por tempo superior a 5 anos, exclusão de outras etiologias;

- Idiopática: exclusão de outras etiologias.

No Brasil, a principal etiologia da IC é a cardiopatia isquêmica crônica associada à hipertensão arterial. Em determinadas regiões geográficas do país e em áreas de baixas condições sócio-econômicas, 
ainda existem formas de IC associadas à doença de Chagas, endomiocardiofibrose e a cardiopatia valvular reumática crônica, que são situações especiais em nossa população ${ }^{1}$.

A IC crônica de etiologia chagásica, no Brasil, acomete 4 a 8\% dos pacientes ambulatoriais, $10 \%$ dos pacientes internados e até $76 \%$ dos pacientes internados em áreas endêmicas. Casos agudos de transmissão vetorial se tornaram excepcionais nas últimas três décadas, porém, a mortalidade anual por doença de Chagas é de aproximadamente 5.500 $\operatorname{casos}^{23}$.

A endomiocardiofibrose ocorre principalmente em áreas tropicais e subtropicais, como África Equatorial, sudeste asiático, Colômbia e nordeste do Brasil e a sintomatologia se inicia na idade jovem. O transplante cardíaco tem sido empregado com sucesso nesta etiologia ${ }^{24}$.

A cardiomiopatia valvar reumática crônica ainda é uma causa frequente de IC no Brasil, embora tenha sido observada redução de novos casos de febre reumática aguda e redução de mortalidade devido à doença reumática, nas últimas três décadas no Brasil ${ }^{25}$.

Em 2006, a IC ou etiologias associadas com IC foram responsáveis por 6,3\% dos óbitos no Estado de São Paulo. Em 42\% dos casos, não foi possível determinar a etiologia, sendo observada cardiomiopatia em $23 \%$ destes, hipertensão arterial em 14\%, doença isquêmica em $9 \%$, doença de Chagas em $8 \%$, choque cardiogênico em $1 \%$, doença pericárdica em 0,04\%, doença de Chagas aguda em 0,006\%, e outras cardiopatias em $3 \%{ }^{26}$. 


\subsection{DIRETRIZES NO DIAGNÓSTICO E TRATAMENTO DA INSUFICIÊNCIA CARDÍACA CRÔNICA}

As evidências para o diagnóstico e tratamento da IC são revisadas frequentemente $e$ as atualizações são iniciadas 0 mais rapidamente possível, baseadas em evidências de grandes estudos.

De acordo com a III Diretriz de IC crônica, publicada em $2009^{1}$, as alterações hemodinâmicas encontradas na IC envolvem resposta inadequada do débito cardíaco e elevação das pressões pulmonar e venosa sistêmica. Inicialmente, este comprometimento do débito cardíaco se manifesta durante o exercício e com a progressão da doença, se torna mais presente mesmo em repouso. O mecanismo responsável pelos sintomas e sinais clínicos da IC pode ser decorrente da disfunção sistólica, diastólica ou de ambas. Cerca de $60 \%$ dos casos está associada à disfunção ventricular esquerda sistólica e $40 \%$ à disfunção diastólica.

A IC crônica pode ser classificada de acordo com a intensidade dos sintomas, em quatro classes propostas pela "New York Heart Association" (NYHA), em 1964, e utilizadas até a atualidade. Estas classes estratificam o grau de limitação imposto pela doença para atividades cotidianas do indivíduo:

- Classe I - ausência de sintomas (dispnéia) durante atividades cotidianas. A limitação para esforços é semelhante à esperada em indivíduos normais;

- Classe II - sintomas desencadeados por atividades cotidianas;

- Classe III - sintomas desencadeados em atividades menos intensas do que as cotidianas, ou pequenos esforços;

- Classe IV - sintomas em repouso. 
A IC também pode ser classificada de acordo com a progressão da doença, o que permite uma compreensão evolutiva da doença e, ainda, serve de base para a identificação de pacientes com indicação de intervenções predominantemente preventivas (estágios A e B), terapêuticas (estágios $\mathrm{C}$ ) ou seleção de pacientes para procedimentos especializados e cuidados paliativos (estágio $\mathrm{D}$ ):

- Estágio A: Inclui pacientes sob o risco de desenvolver IC, mas ainda sem doença estrutural perceptível e sem sintomas;

- Estágio B: Pacientes com lesão estrutural cardíaca, mas ainda sem sintomas;

- Estágio C: Pacientes com lesão estrutural cardíaca e sintomas atuais ou pregressos de IC;

- Estágio D: Pacientes com sintomas refratários ao tratamento convencional, e que requerem intervenções especializadas ou cuidados paliativos ${ }^{1}$.

A IC é diagnosticada a partir dos sinais e sintomas, embora estes apresentem limitações de sensibilidade e especificidade. Os sinais mais específicos incluem pressão venosa elevada e ausculta da terceira bulha cardíaca (B3), muitas vezes não percebida principalmente por profissionais que não são especialistas. Por isso, são utilizados critérios de sistema de pontos (critérios de Boston) ou critérios maiores e menores (critérios de Framingham) com adição da radiografia de tórax, que proporcionam maior acurácia ${ }^{27}$. Além da história e do exame físico, podem ser adicionados: eletrocardiograma (ECG), ecocardiograma (ECO), avaliação laboratorial incluindo peptídeo natriurético do tipo B (BNP), hemograma, função renal e hepática, glicemia, eletrólitos e hormônio tireotrófico $(\mathrm{TSH})^{1}$. Pode ser

BNP: B-type natriuretic peptide; TSH: thyroid-stimulating hormone. Embora as siglas sejam referentes aos termos em ingles, são mantidas no contexto brasileiro. 
solicitada sorologia para chagas, em casos de dados epidemiológicos sugestivos ${ }^{1}$.

O tratamento da IC é baseado em medidas farmacológicas, que incluem inibidores da enzima conversora de angiotensina (IECA), betabloqueadores, bloqueadores dos receptores de angiotensina II (BRA), bloqueadores do canal de cálcio, antagonistas da aldosterona, diuréticos, digitálicos, vasodilatadores, antiarrítmicos, anticoagulantes e antiplaquetários; e medidas não farmacológicas, que incluem mudanças na dieta, restrição de sal e líquidos ingeridos diariamente, adaptação das atividades e monitoramento de sintomas de piora clínica ${ }^{1}$.

Há evidências científicas da redução da morbidade e mortalidade na IC com o tratamento farmacológico, desde que haja seguimento dos pacientes e ajuste das doses quando necessário ${ }^{1}$. No entanto, observa-se que a grande quantidade de medicamentos utilizada, a manutenção do regime terapêutico e o número de doses diárias são fatores que exercem influência direta na adesão ao tratamento ${ }^{28}$.

Diante disso, pesquisadores têm buscado identificar fatores que possam influenciar na adesão ao tratamento farmacológico de pessoas com IC. Uma revisão sistemática da literatura mostrou que alguns fatores como idade, sexo e raça podem influenciar. Além disso, identificaram que pacientes com maior crença no tratamento, com menos ocorrência de efeitos colaterais, com melhor apoio social e melhor relação com o médico são mais aderentes $^{29}$.

As evidências científicas têm mostrado que apesar da importância do tratamento farmacológico da IC, o tratamento não farmacológico tem se tornado parte integrante e indispensável deste complexo regime terapêutico, conforme algumas medidas recomendadas pela III Diretriz da IC:

- Recomendações na composição da dieta, que inclui determinação de limites diários do consumo de carboidratos, 
lipídeos, proteínas, além do valor calórico total da dieta; limite do consumo de sódio de 2 a 3g/dia, principalmente nos estágios mais avançados da doença e na ausência de hiponatremia; restrição de líquidos de acordo com a condição clínica do paciente e dose de diurético prescrito, sendo sugerido de mil a $1.500 \mathrm{ml}$ em pacientes sintomáticos com risco de hipervolemia; abstinência completa de bebida alcoólica; uso de suplemento nutricional em pacientes com baixa ingestão alimentar, má absorção de nutrientes, uso de medicamentos que alteram a síntese ou que aumentam a excreção de nutrientes; controle da ingestão de vitamina $\mathrm{K}$ em pacientes anticoagulados.

- Monitoramento do peso corporal, que deve ser diário. Além disso, o paciente deve ser orientado a considerar redução acima de $6 \%$ em seis meses, pois pode ser indicativo de caquexia cardíaca, assim como o aumento repentino e inesperado de dois ou mais quilos em curto período (três dias), pois pode indicar retenção hídrica.

- Prevenção de fatores agravantes, com cessação do tabagismo e vacinação anual contra Influenza e a cada cinco anos contra Pneumococcus, sobretudo nas localidades de grandes modificações climáticas entre as estações do ano ${ }^{1}$.

A III Diretriz de IC foi atualizada em 2012 para reavaliar as recomendações por meio de uma avaliação criteriosa das pesquisas. Dentre as recomendações estão: a revisão da importância da IC como causa de morte no Brasil; a não recomendação de rotina do telemonitoramento; o surgimento da avaliação familiar como recomendação importante, devido ao caráter familiar de algumas etiologias da IC; a reavaliação da restrição da adição de sal na dieta, já que o valor ideal de sódio a ser usado na dieta não está definido, devendo ser adaptado à situação clínica do paciente; e a 
manutenção do conceito de clínicas de IC, embora os resultados de estudos ainda sejam controversos ${ }^{30}$.

\subsection{DIRETRIZES NO DIAGNÓSTICO E TRATAMENTO DA INSUFICIÊNCIA CARDÍACA DESCOMPENSADA}

A IC descompensada (ICD) é definida como início rápido ou mudança clínica dos sinais e sintomas de IC, resultando na necessidade urgente de terapia ${ }^{31}$.

Apesar dos progressos no diagnóstico e tratamento da IC, os estudos sobre ICD, só passaram a ser expressivos na última década, em que foram publicados grandes registros e também os primeiros ensaios com casuísticas maiores comparando estratégias terapêuticas nesta patologia.

A ICD resulta em hospitalização e modifica a progressão da IC, pois as taxas de mortalidade após um ano da primeira internação são mais elevadas do que em pacientes que nunca foram hospitalizados e permanece como um dos riscos de mortalidade mais importantes ${ }^{32}$. Além disso, a internação por ICD por si gera mais hospitalização, com taxas de 50\% dentro dos 12 meses após alta hospitalar ${ }^{33}$.

De acordo com a II Diretriz Brasileira de Insuficiência Cardíaca Aguda, publicada em 2009 22, a ICD é usualmente caracterizada por congestão pulmonar. No entanto, a apresentação clínica dominante pode ser de baixo débito com hipoperfusão tecidual. Pode ainda, ser precipitada por causas cardiovasculares e não cardiovasculares, como o aumento da póscarga devido à hipertensão pulmonar ou sistêmica; aumento da pré-carga por sobrecarga de volume ou retenção de líquidos; ou falência circulatória por estados de alto débito, como infecção, anemia ou tireotoxicose.

O diagnóstico da ICD é baseado em sinais e sintomas clínicos e amparado por exames complementares, como ECG, radiografia de tórax, 
exames laboratoriais incluindo hemograma, sódio, potássio, ureia, creatinina e glicose. Em casos mais graves, devem ser dosadas enzimas hepáticas, albumina e tempo de protrombina ${ }^{22}$.

O principal sintoma que leva o paciente com ICD a procurar atendimento hospitalar é a dispneia. Como esse é um sintoma também observado em outras afecções, a história prévia de IC torna o diagnóstico bastante provável e a presença de ortopneia e dispneia paroxística noturna também favorece o diagnóstico. Outros sintomas incluem cansaço, fadiga e sintomas digestivos, como anorexia, distensão abdominal e diarreia (em casos de isquemia ou congestão visceral). A severidade dos sintomas na maioria das vezes é avaliada por meio da classificação funcional da NYHA. Apesar da subjetividade, essa classificação é simples e largamente utilizada na prática clínica ${ }^{22}$.

Como os critérios de "Framingham", utilizados no cenário ambulatorial, demonstram acurácia apenas intermediária e os critérios de "Boston" usam um sistema de pontuação semelhante e têm demonstrado desempenho diagnóstico semelhante aos de "Framingham";34; e como recentes registros de IC evidenciaram uma significativa heterogeneidade de apresentações de ICD, o exame físico persiste com absoluta utilidade para caracterizar o paciente com insuficiência cardíaca em quatro perfis hemodinâmicos ${ }^{35}$.

O diagnóstico do perfil clínico-hemodinâmico tem como objetivo definir as condições de volemia e de perfusão nos pacientes com IC aguda. A estimativa da condição hemodinâmica se faz por meio da avaliação de sinais e sintomas de hipervolemia ou hipovolemia e de baixa perfusão periférica à beira do leito. Os pacientes com sintomas e sinais clínicos de congestão ficam denominados como ÚMIDOS; na ausência destes, como SECOS; na presença de sinais de baixo débito, como FRIOS; e os com perfusão periférica mantida como QUENTES. Portanto, temos quatro situações possíveis: 
a) Pacientes congestos sem baixo débito: quente e congesto;

b) Pacientes congestos com baixo débito: frio e congesto;

c) Pacientes sem sinais de congestão com baixo débito: frio e seco;

d) Pacientes sem sinais de congestão ou de baixo débito: quente e seco ${ }^{35,36}$

A identificação do perfil clínico-hemodinâmico na admissão hospitalar tem importância não somente na determinação da estratégia terapêutica, como também tem valor prognóstico ${ }^{22}$. Sendo pior nos pacientes quentes e congestos e frios e congestos, quando comparados aos quentes e $\operatorname{secos}^{36}$.

O perfil hemodinâmico mais encontrado nos pacientes com ICD é de hipervolemia em cerca de $80 \%$ dos pacientes, dos quais $20 \%$ apresentam sinais de baixo débito e $7 \%$ a $10 \%$ apresentam-se hipovolêmicos ${ }^{37}$.

Como a avaliação clínico-hemodinâmica apresenta uma acurácia de $50 \%$ a $60 \%$ na capacidade de estimar a real condição hemodinâmica, por vezes necessitamos complementar a avaliação com outros métodos não invasivos, como BNP e ECO, para estabelecer a melhor estratégia terapêutica, evitando a utilização inadequada de diuréticos ou vasodilatadores em excesso em pacientes não congestos ou deixando de utilizar inotrópicos em pacientes com reconhecido baixo débito ${ }^{22}$.

O tratamento da ICD tem o objetivo clínico dividido em duas fases: a precoce com o paciente na sala de emergência do pronto-socorro, priorizando o alívio dos sintomas e a estabilização hemodinâmica; a tardia com o paciente na enfermaria e ações voltadas à melhora da morbimortalidade em longo prazo. O objetivo hemodinâmico é que os pacientes alcancem o perfil "quente e seco", sendo importante o ajuste da pressão arterial sistêmica, tanto com o uso de vasopressores, inotrópicos e 
reposição volêmica nos pacientes hipotensos, quanto com o uso de vasodilatadores, nos pacientes hipertensos. Dessa forma, a abordagem terapêutica é estabelecida a partir da combinação de três principais fatores: fator causal da ICD, pressão arterial e avaliação clínico-hemodinâmica, podendo ser utilizados: suporte respiratório, vasodilatadores, morfina, diuréticos, inotrópicos e reposição volêmica ${ }^{22}$.

Recentemente, uma revisão sistemática forneceu uma síntese das estratégias utilizadas no manejo da ICD. O resultado mostrou que independentemente da etiologia, da causa subjacente ou da fração de ejeção, a maioria das internações hospitalares continua sendo resultado da piora da ICC. A estratificação dos quatro perfis hemodinâmicos pelo grau de congestão ("seco" ou "úmido") e adequação da perfusão ("quente" ou "frio") mantém-se útil para guiar o tratamento e predizer o prognóstico. O principal objetivo do tratamento precoce continua sendo o alívio da congestão, utilizando diuréticos de alça. No entanto, surgem novas modalidades, tais como ultrafiltração veno-venosa. Para os pacientes com hipoperfusão, deve ser considerado o uso de inotrópicos, porém, a decisão de utilizar vasodilatadores ou inotrópicos deve ser ponderada, devido à necessidade de monitorização hemodinâmica invasiva. Dessa forma, o uso rotineiro de inotrópicos deve ser desencorajado e quando for usado, os benefícios hemodinâmicos devem ser equilibrados contra a sua tendência para aumentar os efeitos adversos. Os estudos epidemiológicos continuam a enfatizar o mau prognóstico após um evento de ICD. Os autores recomendam mais estudos para melhorar a nossa compreensão sobre o manejo específico da $I C D^{38}$.

Dados de um estudo norte-americano mostram que os fatores precipitantes mais comuns da hospitalização por IC são o descumprimento do regime médico na restrição de sódio e/ou de líquido, isquemia miocárdica aguda, controle inadequado da pressão arterial elevada, arritmias cardíacas (principalmente fibrilação atrial), introdução recente de novos medicamentos (principalmente beta-bloqueadores e diltiazen), embolia pulmonar, uso de 
antiinflamatórios não hormonais, abuso de álcool ou drogas ilícitas, descompensação endócrina (diabetes, hipertireoidismo ou hipotireoidismo) e infecções por pneumonia ou infecções virais ${ }^{39}$.

Em estudo conduzido no Brasil, os autores ressaltam que a principal causa das hospitalizações por ICD é o tratamento inadequado, devido à baixa adesão ao tratamento ou devido à prescrição médica não otimizada. Esses dados indicam que medidas de orientação e início precoce do tratamento poderiam ter grande impacto na qualidade de vida dos pacientes, menor tempo de hospitalização e menos gastos para o serviço de saúde $^{40}$. Neste sentido, considera-se a importância das medidas voltadas ao tratamento da IC, sejam farmacológicas ou não farmacológicas, as quais devem incluir ações educativas. Reafirma-se a necessidade de educação em saúde, a fim de promover a adaptação e realização do autocuidado pelos pacientes com IC.

Neste contexto, o cuidado de enfermagem ao paciente com IC agrega ações e intervenções para o manejo e controle da doença, visto que a abordagem médica pontua prescrições de medicamentos, exames diagnósticos e de controle, além de medidas não farmacológicas para 0 tratamento e controle da IC.

A abordagem do enfermeiro se volta para o acompanhamento das pessoas com IC, o ensino do autocuidado, as orientações relacionadas ao conhecimento sobre a doença, o manejo e a adesão ao tratamento, além de possibilitar que as pessoas com IC expressem suas dúvidas, suas experiências e vivências da doença, de modo a estabelecer uma relação de vínculo e empatia e de interação capaz de estabelecer um contrato terapêutico para melhor manejo da doença ${ }^{41}$.

A seguir, apresentamos a conceituação de adesão ao tratamento e autocuidado, além de um panorama dos estudos voltados à adesão ao tratamento e autocuidado de pessoas com IC a partir de intervenções educativas, tendo o enfermeiro como integrante da equipe multiprofissional. 


\subsection{A ADESÃO AO TRATAMENTO E O AUTOCUIDADO COMO FOCO DAS AÇÕES EDUCATIVAS EM PESSOAS COM IC}

\subsubsection{Conceitos de adesão ao tratamento e autocuidado}

Há um interesse crescente de pesquisadores em compreender as questões relacionadas à adesão ao tratamento e ao autocuidado específico para o controle da IC.

Os estudos voltados para a avaliação da adesão ao tratamento e para $\mathrm{O}$ autocuidado em pessoas com IC nos conduzem à reflexão sobre 0 conceito e interpretação desses, que são objetos de estudo de enfermeiros e outros profissionais que integram a equipe de saúde.

Para a Organização Mundial de Saúde (OMS), a adesão ao tratamento pode ser caracterizada como a extensão em que o comportamento do indivíduo, em termos de tomar o medicamento, realizar mudanças no estilo de vida e comparecer às consultas médicas coincide com o conselho médico ou de saúde. É um fenômeno multidimensional determinado pela interação de cinco fatores: sistema e equipe de saúde, fatores sócio-econômicos, fatores relacionados ao tratamento, ao paciente e à doença ${ }^{42}$.

A adesão a tratamentos crônicos pode ser conceituada como o grau em que o comportamento de uma pessoa representado pela ingestão de medicamentos, o seguimento da dieta, as mudanças no estilo de vida corresponde e concorda com as recomendações de um médico ou outro profissional de saúde ${ }^{43,44}$.

Existem outras terminologias utilizadas como sinônimos para adesão, como aderência, observância, complacência, fidelidade e "compliance", que seria a "obediência participativa, ativa, do paciente à 
prescrição médica", entendendo-se por prescrição não apenas os medicamentos, mas também todos os cuidados ou providências recomendados pelo médico ou outro profissional de saúde. No entanto, muitos autores preferem a palavra adesão, porque "compliance" sugere que o paciente segue passivamente as "ordens" do médico e que o plano de tratamento não é baseado na aliança ou contrato estabelecido entre ambos $^{45}$.

Em revisão sobre os conceitos de adesão, autores ressaltam que as definições de adesão devem sempre abranger e reconhecer a vontade do indivíduo em participar e colaborar com seu tratamento, o que não é abordado em algumas concepções ${ }^{46}$. $\mathrm{O}$ conceito de adesão neste contexto nos direciona ao conceito de autocuidado.

"O autocuidado é definido como a decisão e as estratégias desenvolvidas pelo indivíduo, a fim de manter a vida, a saúde e o bem-estar" (Orem, 1995) ${ }^{47}$.

Este conceito de autocuidado deriva da teoria de enfermagem do déficit do autocuidado, que é composta de três teorias interrelacionadas: do autocuidado, do déficit de autocuidado e dos sistemas de enfermagem.

$\mathrm{Na}$ teoria do autocuidado incorpora-se o conceito dos requisitos de autocuidado: universais, que são comuns aos seres humanos, auxiliandoos em seu funcionamento; desenvolvimentais, que ocorrem quando há a necessidade de adaptação às mudanças que surgem na vida do indivíduo; por desvios de saúde, que acontece quando o indivíduo em estado patológico necessita adaptar-se a tal situação ${ }^{47}$.

Os requisitos para o autocuidado por desvio de saúde são: busca e garantia de assistência médica adequada; conscientização e atenção aos efeitos e resultados de condições e estados patológicos; execução de medidas prescritas pelo médico e conscientização de efeitos desagradáveis dessas medidas; modificação do autoconceito (e da autoimagem) na 
aceitação de si como estando num estado especial de saúde; aprendizado da vida associado aos efeitos de condições e estados patológicos, bem como de efeitos de medidas de diagnósticos e tratamentos médicos, num estilo de vida que promova o desenvolvimento contínuo do indivíduo ${ }^{47}$.

Para se entender a teoria do autocuidado é necessário definir os conceitos relacionados, como os de autocuidado e de ação de autocuidado. Autocuidado é a atividade que os indivíduos praticam em seu benefício para manter a vida, a saúde e o bem estar. Ação de autocuidado é a capacidade do homem em engajar-se no autocuidado. Alguns fatores são condicionantes básicos para as ações de autocuidado: idade, sexo, estado de desenvolvimento, estado de saúde, orientação sócio-cultural e fatores do sistema de atendimento de saúde ${ }^{48}$.

Baseadas na teoria de Orem ${ }^{47}$, Jaarsma et $\mathrm{al}^{49}$ consideram a IC como um desvio de saúde, para o qual são necessárias ações de autocuidado específicas. Dentre as quais, incluem o cumprimento e adesão ao tratamento farmacológico, dieta e exercício, monitoramento dos sintomas de piora clínica, além de peso diário e busca por ajuda, quando os sintomas ocorrem.

Riegel et $\mathrm{al}^{50}$ definem o autocuidado como um processo de tomada de decisão que os pacientes usam na escolha de ações que mantém a estabilidade fisiológica (monitoramento de sintomas e adesão ao tratamento) e a resposta diante da ocorrência de sintomas.

Em revisão sistemática recente, Riegel et $\mathrm{a}^{51}$ descrevem as ações de autocuidado necessárias a pessoas com IC: uso correto dos medicamentos, monitoramento e interpretação dos sintomas de piora clínica, adequação da dieta e líquidos, restrição de álcool, peso diário, exercícios, cessação do tabagismo e comportamentos preventivos como higiene e imunização. 
Dessa forma, a adesão às orientações para o tratamento correto da IC depende, em grande parte, do conhecimento e compreensão destas orientações, por parte dos pacientes e de seus familiares. Somados a isso, é necessário que o paciente faça o julgamento correto para monitorizar os sintomas de piora da IC, que é uma síndrome passível de frequentes descompensações. Depende ainda, do conhecimento e habilidade dos pacientes para manter estes comportamentos. O conjunto de todas estas ações é denominado de autocuidado, que pode ser definido como um processo cognitivo ativo ao qual o paciente é submetido para manter ou manejar a doença e os quadros de descompensação ${ }^{52}$.

\subsubsection{Ações educativas voltadas para o autocuidado e adesão ao tratamento da IC}

Revisão da literatura para identificar estudos sobre IC realizados por enfermeiros no Brasil mostrou que os fatores que motivaram tais trabalhos estavam relacionados às características da doença, em razão de sua cronicidade e progressão e às características dos pacientes com IC quanto ao autocuidado, adesão ao tratamento e qualidade de vida ${ }^{53}$.

Diante disso, buscou-se conhecer o panorama internacional dos estudos realizados por enfermeiros na última década, voltados para o autocuidado e adesão ao tratamento.

Em 1999, na Europa, foi realizado um estudo com o objetivo de testar o efeito da educação e apoio do enfermeiro no autocuidado em pacientes com IC, em ambiente hospitalar. Foram randomizados 179 pacientes internados por IC. O grupo controle $(\mathrm{N}=95)$ recebeu cuidado usual e o grupo intervenção $(\mathrm{N}=84)$ recebeu também educação intensiva por enfermeira e visita domiciliar após sete dias de alta. Os resultados mostraram melhora significativa das ações de autocuidado do grupo intervenção $0^{54}$. 
Outro estudo ${ }^{55}$, publicado no mesmo ano, avaliou o nível de conhecimento e adesão ao tratamento em pacientes com IC; determinou os fatores associados, a partir de um levantamento das necessidades de avaliação de novos pacientes em uma clínica de IC. Os autores identificaram que os pacientes que haviam recebido aconselhamento sobre autocuidado dos médicos ou enfermeiros tinham maior conhecimento sobre IC. No entanto, observaram que pacientes tinham dificuldades em absorver e aplicar o que era ensinado.

Neste contexto, indicar as necessidades de educação em saúde passou a ser visto como algo complexo, levando a questionamentos sobre $o$ que ensinar aos pacientes. Estudo descritivo com 30 pacientes avaliou as principais necessidades educacionais sob a ótica dos pacientes, médicos e enfermeiros. O grupo de pacientes listou as questões relacionadas ao conhecimento sobre a doença como as mais importantes. No entanto, os médicos concordaram com a escolha dos pacientes em $13 \%$ e os enfermeiros em $23 \%$, demonstrando que as necessidades de educação em saúde apontadas pelos profissionais podem não atender às expectativas e necessidades dos pacientes ${ }^{56}$.

Em estudos realizados posteriormente, pesquisadores afirmaram que além de orientar, seria necessário que programas de saúde voltados a pessoas com IC, usassem instrumentos para avaliar o impacto de suas intervenções, isto é, a satisfação dessas pessoas com a informação recebida e o conhecimento que elas adquiriam sobre a doença e tratamento ${ }^{57,58}$. Além disso, pesquisadores passaram a desenvolver instrumentos para avaliar o conhecimento das pessoas e programas direcionados às necessidades de grupos específicos ${ }^{59}$.

Foram desenvolvidos ou adaptados diversos instrumentos, no Brasil e em outros países, capazes de mensurar variáveis psicossociais como crenças de saúde, qualidade de vida, depressão, funcionalidade, adesão e autocuidado ${ }^{60,61,62}$. 
Neste contexto, em 2002, foi desenvolvido o instrumento "European Heart Failure Self Care Behaviour Scale" (EHFScBS), para avaliar ações de autocuidado específicas para IC, que incluem adesão ao tratamento farmacológico, dieta e exercício, monitoramento dos sintomas, além de peso diário e busca por ajuda, quando os sintomas ocorrem ${ }^{49}$.

Em 2009, Ávila et al. ${ }^{63}$ realizaram tradução e validação do instrumento original, para o português do Brasil, a partir de tradução, reprodutibilidade e avaliação da consistência interna, aplicando-o em 124 pacientes. Concluíram que o instrumento é reprodutível para avaliar as ações de autocuidado da população brasileira com IC, tornando-se uma ferramenta útil, rápida e de fácil aplicabilidade em qualquer serviço de saúde.

No mesmo ano, Bocchi et al ${ }^{64}$ apresentaram resultados da educação repetitiva e prolongada em pessoas com IC, a partir da aplicação de um questionário de adesão ao tratamento, que aborda: uso correto dos medicamentos, peso diário, restrição de sal e líquidos, ingestão de bebida alcoólica e assiduidade em consultas e exames. Os resultados mostraram a redução de hospitalização não programada, dos dias de internação e da necessidade de atendimento de emergência, além de melhora na qualidade de vida. No entanto, os autores afirmam que os mecanismos subjacentes na melhora dos resultados continuam limitados.

Dessa forma, principalmente na última década, diferentes estratégias de enfermagem, baseadas na educação e no seguimento intensivo de pacientes com IC têm sido empregadas. E para avaliar a eficácia destas estratégias, são utilizados os instrumentos de medidas psicossociais, dentre eles, instrumentos para mensurar a adesão ao tratamento e o autocuidado.

Em estudo publicado em 2005, enfermeiros avaliaram o impacto e custo-efetividade de intervenções com lembretes via email no autocuidado de pacientes com IC. O grupo controle recebeu cuidado usual; os outros 
grupos receberam intervenção básica baseada em seis diretrizes e intervenção ampliada baseada em seis diretrizes, além de cartão com lembretes sobre medicamentos, comunicação com equipe e guia de autocuidado. A intervenção teve efeito positivo sobre o conhecimento, autocuidado, resultados clínicos e funcionais e reduziu custo ${ }^{65}$.

Em estudo publicado em 2006, uma equipe multidisciplinar avaliou o impacto em longo prazo da intervenção multidisciplinar domiciliar (médico, enfermeiro e farmacêutico) comparada aos cuidados usuais após alta hospitalar em idosos frágeis com IC. Houve diferença significativa na mortalidade entre os grupos no período de seis meses. A média de sobrevida foi quase o dobro no grupo intervenção, associada à redução de 40\% no risco de evento fatal. O grupo intervenção teve menos readmissões a curto e médio prazo. Houve melhor custo benefício por ano de vida adicional adquirido. Os autores concluíram que a intervenção domiciliar por enfermeiro e farmacêutico tem potencial para alargar o horizonte de sobrevida em pessoas com IC, com menos ocorrência de readmissões. Os resultados reforçaram o conceito de educação por equipe multiprofissional e com estratégias que enfatizem a compreensão sobre a doença e o tratamento e sobre o autocuidado, aprendendo a buscar auxílio da equipe de saúde em caso de piora clínica ${ }^{66}$.

Em estudo publicado em 2007, médicos e enfermeiros buscaram determinar se uma intervenção intensiva combinada de médico e enfermeiro reduziria hospitalizações por IC e melhoraria o estado funcional. O grupo controle recebeu cuidado usual no ambulatório e o grupo intervenção recebeu visitas domiciliares de médico e enfermeiro, que informavam sobre tratamento e doença, reconhecimento de sintomas e quando procurar serviço de saúde. Houve melhora do autocuidado em 12 meses e redução do custo no grupo intervenção. Os autores concluíram que o programa de gerenciamento intensivo realizado por médico e enfermeiro pode reduzir internações, melhorar estado funcional, enquanto diminui os custos de saúde ${ }^{67}$. 
Em 2008, foi publicado estudo realizado na Europa, envolvendo 1023 pacientes, que comparou três grupos: um grupo controle (acompanhamento por um cardiologista) e dois grupos de intervenção com suporte básico ou intensivo adicionais por uma enfermeira especialista no tratamento de pacientes com IC. Os desfechos primários estudados foram morte ou reinternação por causa da IC e número de dias perdidos por morte ou hospitalização. Os resultados mostraram que o suporte adicional por uma enfermeira especialista, reduziu os desfechos combinados de morte e hospitalização por IC, em comparação com o padrão de acompanhamento. Houve redução discreta na mortalidade, acompanhada por um ligeiro aumento no número de internações curtas em ambos os grupos de intervenção. Os autores sugerem que apesar do desfecho não ser totalmente favorável, o conceito de programa de aconselhamento não deve ser abandonado, mas acreditam que um modelo não serve para todos os pacientes ou todos os sistemas de saúde ${ }^{68}$.

Em estudo publicado em 2009, médicos e enfermeiros buscaram determinar o efeito do reforço telefônico comparado ao cuidado usual no ambulatório. Os autores concluíram que a intervenção educativa associada a reforço telefônico por enfermeiro tem efeitos positivos sobre readmissões, qualidade de vida e ações de autocuidado ${ }^{69}$.

Em 2010, médicos e enfermeiros buscaram demonstrar a eficácia de uma intervenção educativa domiciliar em pacientes com IC em longo prazo. Os autores concluíram que pacientes com IC que recebem intervenção educacional do enfermeiro após a alta hospitalar tem menos readmissões hospitalares e mostram uma tendência à melhora da qualidade de vida ${ }^{70}$. No mesmo ano, outro estudo buscou avaliar o impacto de um programa de suporte em pacientes com IC e limitação funcional em relação ao autocuidado, qualidade de vida e aspectos psicossociais. $\mathrm{O}$ grupo controle recebeu cuidado usual pelo médico do ambulatório e o grupo intervenção participou de encontros em grupo conduzidos por enfermeiro especialista, que abordava estabelecimento de metas de saúde, 
interpretação de sintomas e motivação para mudar comportamentos e crenças. O Programa melhorou em curto prazo o autocuidado, a qualidade de vida e a gestão cognitiva de sintomas $^{71}$.

Ainda em 2010, estudo controlado, envolvendo 902 pacientes com IC leve a moderada e função sistólica preservada e reduzida, buscou determinar o valor do aconselhamento sobre manejo adicionado à educação convencional em pessoas com IC, em comparação a apenas educação convencional. Os autores concluíram que a adição de aconselhamento sobre autocuidado não reduziu morte ou hospitalização por IC. No entanto, reafirmam a necessidade de continuidade de estudos, diante da importância epidemiológica da IC. Sugerem abordagens inovadoras e de baixo custo no contexto ambulatorial e estudos futuros que avaliem os benefícios do aconselhamento sobre manejo em pacientes de baixa renda ${ }^{72}$.

Estudo desenvolvido por Freitas $^{73}$, em 2010, em 42 pacientes acompanhados em um hospital de alta complexidade em São Paulo, mostrou que o conhecimento dos participantes da pesquisa "é permeado pela experiência de ter e viver com a doença e está voltado para os sinais e sintomas e o cuidado diário para controle da IC, o que sugere um conhecimento mais vivido do que adquirido conceitualmente e não advém de conhecimentos técnicos e científicos, mas da vivência e do manejo diário da IC". A autora afirmou que "o acompanhamento de enfermagem a pessoas com IC no ambulatório é fundamental e deve englobar ações voltadas à educação em saúde e à aprendizagem do autocuidado. Visto que a educação não se faz de uma só vez e o modo de viver da pessoa só pode ser mudado quando, de certa forma, ela já está aberta à possibilidade de mudança, é necessário sensibilizar o paciente com IC para que encontre em si razões próprias que o levem a buscar o conhecimento e melhorar o manejo da doença".

Em 2011, estudo conduzido por enfermeiras brasileiras, comparou a intervenção de enfermagem iniciada no hospital, seguida 
por monitoramento telefônico com a intervenção única no hospital, em pacientes com IC. Foram utilizados instrumentos para avaliar o conhecimento sobre a IC e o autocuidado na primeira visita e após três meses. As autoras concluíram que a intervenção educativa do enfermeiro iniciada no hospital melhora o conhecimento e o autocuidado, independente do contato telefônico, pois não houve diferença estatisticamente significativa entre os grupos nas variáveis estudadas. Os autores recomendam estudos com outras formas de monitorização após a alta ${ }^{74}$.

Em 2012, enfermeiros avaliaram a eficácia de entrevista motivacional na melhora do autocuidado em pacientes com IC. A intervenção melhorou o comportamento dos pacientes com IC em relação ao autocuidado, porém os autores recomendam estudos futuros que confirmem estes resultados preliminares, já que os resultados mostraram apenas o efeito preliminar de uma intervenção $0^{75}$.

A análise dessas produções nos mostra que temos avançado em termos de compreensão sobre os aspectos fundamentais no manejo da IC. Temos valorizado a adesão ao tratamento e o autocuidado e, diante disso, empregado diferentes abordagens educativas, em diferentes grupos de pacientes e avaliado diferentes desfechos.

Temos aprendido como avaliar a eficácia das intervenções, utilizando instrumentos capazes de mensurar variáveis psicossociais, partindo tanto da elaboração e validação quanto da aplicação de instrumentos validados em estudos anteriores.

Apesar das diferentes abordagens ao paciente com IC demonstrarem resultados favoráveis sobre a adesão ao tratamento, autocuidado, qualidade vida, internações não planejadas, dias de internação e mortes por IC, existem lacunas sobre os mecanismos que explicam estes resultados. Também, observamos poucos estudos voltados aos pacientes com ICD, sendo mais frequentes os estudos no contexto ambulatorial. 
No estudo "REMADHE"64, os autores avaliaram a eficácia da abordagem educativa utilizando o instrumento "Questionário de Aderência em Pacientes com Insuficiência Cardíaca", em ambiente ambulatorial, para avaliar a adesão ao tratamento dos pacientes, considerando as ações dos últimos quinze dias. No entanto, este instrumento ainda não havia sido aplicado em pacientes com ICD.

Diante da importância do autocuidado no tratamento da IC e dos aspectos considerados relevantes nos estudos citados, acreditamos que seria interessante investigar o autocuidado a partir da aplicação do "Questionário de Aderência em Pacientes com IC", já utilizado em nossa população, além de questionário que abordasse ações de autocuidado específicos para IC, perfil clínico e sociodemográfico nos dois contextos: na clínica especializada (ambulatório), com pacientes compensados e no pronto-socorro, com pacientes descompensados; possibilitando a comparação entre os dois grupos em relação às ações de autocuidado específicas para IC, adesão ao tratamento e outros fatores que possam estar relacionados à ocorrência de ICD.

Surge o interesse em desenvolver uma investigação para responder às perguntas:

- As pessoas com IC realizam o autocuidado específico para o controle da doença?

- Existe diferença entre o autocuidado de pessoas com IC em clínica especializada e pronto-socorro?

- Quais os principais fatores precipitantes de descompensação em pessoas com IC no pronto-socorro?

- Quais os principais desfechos em seis meses em pessoas com IC em clínica especializada e pronto-socorro? 


\section{Objetivos}




\section{OBJETIVOS}

- Caracterizar pacientes com Insuficiência Cardíaca atendidos em clínica especializada e em pronto-socorro, conforme perfil sócio-demográfico, perfil clínico, tempo de conhecimento da doença e internações no último ano.

- Identificar ações de autocuidado específicas em pessoas com insuficiência cardíaca em clínica especializada e prontosocorro;

- Verificar a diferença entre o autocuidado de pessoas com insuficiência cardíaca em clínica especializada e prontosocorro;

- Identificar os possíveis fatores precipitantes de descompensação em pessoas com insuficiência cardíaca no pronto-socorro. 
48

Metodología 


\section{METODOLOGIA}

\subsection{DELINEAMENTO DO ESTUDO}

Trata-se de um estudo descritivo correlacional, com finalidade de observar e documentar aspetos de uma situação, além de descrever o relacionamento entre as variáveis ${ }^{76}$. $\mathrm{A}$ abordagem é quantitativa, orientada à busca da magnitude e causas de fenômenos, além de verificação dos resultados, para os quais assume uma realidade estatística ${ }^{77}$.

\subsection{LOCAL DO ESTUDO}

O estudo foi realizado no ambulatório e no pronto-socorro do Instituto do Coração do Hospital das Clínicas da Faculdade de Medicina da Universidade de São Paulo (InCor), localizado na cidade de São Paulo.

O InCor é parte do Hospital das Clínicas (HC) e campo de ensino e de pesquisa para a Faculdade de Medicina da Universidade de São Paulo (USP). É considerado hospital público universitário de alta complexidade, especializado em cardiologia e pneumologia. Além de ser um pólo de atendimento, desde a prevenção até o tratamento, também se destaca como um grande centro de pesquisa e de ensino ${ }^{78}$.

Conforme dados do Relatório Anual de Atividades do $\operatorname{lnCor}{ }^{78}$, no contexto assistencial, o InCor atende prioritariamente pacientes financiados pelo convênio SUS (79\%), mediante encaminhamento médico das unidades básicas de saúde, do Complexo Hospital da Clínicas, para o qual funciona como referência em cardiologia, e dos demais hospitais, dentro do sistema de referência e contrarreferência e hierarquização do SUS. Os demais pacientes atendidos no InCor (21\%) são oriundos de convênios e particulares. As áreas do hospital diretamente envolvidas com o estudo 
foram a Unidade Clínica de Insuficiência Cardíaca e o Serviço de Emergência.

A Unidade Clínica de Insuficiência Cardíaca desenvolve programas integrados de assistência, ensino e pesquisa em pessoas com insuficiência cardíaca. O atendimento dessa Unidade corresponde a 5,5\% do total de consultas médicas realizadas nos ambulatórios de especialidade, 0 que equivale a 605 consultas médicas mensais, totalizando 7.264 consultas realizadas no ambulatório de especialidades, no ano de $2009^{79}$.

O serviço de emergência atende preferencialmente pacientes referidos mediante encaminhamento médico das unidades básicas de saúde e do complexo $\mathrm{HC}$, para o qual funciona como referência em cardiologia. Dedica-se ao tratamento do cardiopata crônico na fase aguda da doença, portanto, é o local onde são atendidos os pacientes da Unidade Clínica de Insuficiência Cardíaca, em casos de eventos agudos. O fluxo de atendimento é determinado pelas necessidades do tratamento: atendimento e observação na própria unidade, internação ou acompanhamento ambulatorial no próprio hospital ou em outra unidade de saúde ${ }^{79}$.

O Incor foi escolhido como local de coleta de dados por se tratar de uma Instituição de referência em assistência, ensino e pesquisa em cardiologia no Brasil.

\subsection{SUJEITOS DA PESQUISA}

Foram convidados a participar do estudo, pacientes em consulta ambulatorial na Unidade Clínica de Insuficiência Cardíaca e pacientes admitidos no pronto-socorro com diagnóstico de IC descompensada, de ambos os sexos. 


\subsubsection{Critérios de inclusão}

- Ter idade igual ou superior a 18 anos e apresentar capacidade de compreensão e comunicação.

- Concordar em participar da pesquisa, oficializando por meio da assinatura do Termo de Consentimento Livre e Esclarecido (Anexo 1).

- Ter diagnóstico de IC sistólica há pelo menos doze meses².

- Ser paciente da instituição há pelo menos doze meses ${ }^{3}$.

\subsubsection{Critérios de exclusão}

- Ter sequelas neurológicas e cognitivas que prejudicassem o entendimento do instrumento.

- Estar em tratamento dialítico e em fila de transplante, por apresentarem doenças e/ou comorbidades que poderiam modificar as interpretações da entrevista.

- Estar participando de protocolos de pesquisa no momento do estudo para que não houvesse viés de resultados e conflito de interesses.

\section{$4.4 \quad$ INSTRUMENTOS DE COLETA DE DADOS}

Para a coleta de dados, foram utilizados três instrumentos.

2 Foi definido tempo mínimo de diagnóstico por considerar que o paciente precisa de um período de adaptação à situação de saúde. Foi considerada IC sistólica em pacientes com fração de ejeção do ventrículo esquerdo (FEVE) $<50 \%$.

3 Foi definido tempo mínimo de acompanhamento na instituição, por considerar que o paciente precisa receber orientação prévia sobre o tratamento para ser avaliado quanto a ações de autocuidado. 
O Instrumento 1 (Apêndice 1), é composto por três partes, descritas a seguir:

- Parte I - aborda perfil sócio-demográfico, com dados relativos a: sexo, situação conjugal e coabitantes, religião, anos de estudo, situação de trabalho e renda.

- Parte II - aborda conhecimento da doença, internações e atitudes adotadas diante da IC: tempo de conhecimento sobre a doença, história de internações por IC descompensada nos últimos doze meses, dificuldade e local para controle de peso, além de questões sobre ações diante de piora clínica (ganho de peso, dispneia e edema) e vacinação anual contra gripe, baseados nas ações de autocuidado específicas para IC, conforme publicações de Jaarsma et al ${ }^{49}$, Riegel et al ${ }^{50} \mathrm{e}$ tópico sobre tratamento não farmacológico da III Diretriz Brasileira de ICC $^{1}$.

- Parte III - aborda perfil clínico, por meio de consulta ao prontuário, com dados relativos a: etiologia, doenças associadas, medicamentos associados, classe funcional, dados do ECO, exames laboratoriais e dispositivos implantados, baseados nas recomendações da III Diretriz Brasileira de ICC ${ }^{1}$.

Como Instrumento 2, foi utilizado o "Questionário de Aderência em Pacientes com IC" (Anexo 2), composto por 10 itens que abordam: uso correto dos medicamentos, peso diário, restrição de sal e líquidos, ingestão de bebida alcoólica e assiduidade em consultas e exames. Cada item do questionário de adesão é pontuado numa escala que varia de 0 a 6 , sendo 0 o pior nível de adesão e 6 o melhor nível. O Total de Pontos do "Questionário de Aderência em Pacientes com IC" foi considerado a variável principal do estudo. 
Embora tenha sido utilizado o instrumento "Questionário de Aderência em Pacientes com IC", adotamos neste estudo o termo "adesão", considerando a literatura ${ }^{42-46}$.

A escolha pela utilização dos dois instrumentos descritos se justifica pela importância da avaliação da adesão ao tratamento, a partir da aplicação de um instrumento validado em nossa população (anexo 2) ${ }^{64}$, juntamente com a avaliação de ações de autocuidado necessárias às pessoas com IC ${ }^{49,50}$.

O Instrumento 3 (Apêndice 2), incluído após análise inicial dos resultados, é composto de avaliação clínico-hemodinâmica com classificação em quatro perfis, descritos a seguir:

- Pacientes sem sinais de congestão ou de baixo débito: quente/seco;

- Pacientes congestos sem baixo débito: quente/úmido;

- Pacientes congestos com baixo débito: frio/úmido;

- Pacientes sem sinais de congestão com baixo débito: frio/seco;

Estes perfis atendem às recomendações da II Diretriz Brasileira de IC aguda ${ }^{26}$ no que se refere à monitorização não invasiva; ao tratamento e desfechos que incluíram; tempo de internação, transferência, alta e óbito. Foi aplicado apenas no grupo $\mathrm{B}$, a fim de descrever melhor a gravidade e os desfechos. Os grupos A e B são descritos a seguir.

\subsection{DEFINIÇÃO DA AMOSTRA}

O cálculo amostral (n) foi realizado utilizando a variável Total de Pontos do "Questionário de Aderência em Pacientes com IC" como variável principal do estudo, sendo considerado como tendo um desvio padrão igual 
a 10,0 pontos, baseado no estudo "Remadhe" ${ }^{68}$. Utilizamos o teste t-Student como método estatístico para o cálculo do $\mathbf{n}$, considerando um poder de $90 \%$, significância de $5 \%$ e uma diferença detectável igual a 6,0 pontos entre os grupos para aquela variável. Com isso, encontramos um $\mathbf{n}$ de 60 pacientes para cada grupo, totalizando 120 pacientes que foram entrevistados.

\subsection{PROCEDIMENTOS DE COLETA DE DADOS}

Os dados foram coletados de julho a novembro de 2011.

Os participantes da pesquisa, após seleção prévia pelo prontuário e de acordo com os critérios de inclusão foram convidados e esclarecidos pela pesquisadora a participarem do estudo.

A coleta de dados foi realizada por meio de entrevista individual, na qual os pacientes responderam os dois questionários: Instrumento 1 e 2. Estes instrumentos foram preenchidos pela pesquisadora em dois cenários:

- Unidade de Clínica de Insuficiência Cardíaca (ambulatório): foram coletados os dados no período de julho a agosto de 2011. Os pacientes foram abordados após atendimento médico ambulatorial (consulta agendada) e conduzidos a um dos consultórios disponíveis no ambulatório. Este grupo de pacientes foi denominado Grupo A.

- Unidade do Serviço de Emergência (pronto-socorro): os dados foram coletados no período de agosto a novembro de 2011. Os pacientes foram entrevistados na área de observação, após atendimento inicial e estabilização do quadro clínico, tendo sido respeitados e garantidos a assistência ao paciente e o trabalho dos profissionais. Este grupo de pacientes foi denominado Grupo B. 


\subsection{ANÁLISE DOS DADOS}

Os dados coletados foram lançados nos softwares R 2.14.1 e Microsoft Office Excel 2010, sendo gerados tabelas e relatórios. Em seguida, foram analisados por meio de frequência absoluta e relativa das variáveis categóricas, com os respectivos valores de $p$ do Teste Exato de Fisher ${ }^{80}$, para avaliar existência de associação significativa entre estas e os Grupos A e B.

Para as variáveis contínuas, apresentamos medidas de posição, médias, desvio-padrão e intervalos de confiança para a média e para os Grupos, bem como Teste t-student para comparação entre as médias dos Grupos $^{81}$. Nos casos onde se rejeitou a hipótese de normalidade da variável em questão, segundo o teste de Kolmogorov-Smirnov, apresentamos o teste não paramétrico para comparação de escalas de Mann-Whitney ${ }^{82}$.

Utilizando as variáveis que formam o questionário proposto para o trabalho, realizamos a análise da consistência interna das respostas através do Alpha de Cronbach $^{83}$, bem como a importância de cada uma das questões para avaliar a adesão dos pacientes com IC. Para a análise inferencial foi considerado um nível de significância de $5 \%(\alpha=0,05)$ e todos os testes tiveram conclusão sob hipótese bicaudal.

\subsection{ASPECTOS ÉTICOS}

O projeto de pesquisa foi encaminhado para as áreas envolvidas, Unidade Clínica de IC e Serviço de Emergência. Após ciência, aprovação e assinatura dos respectivos responsáveis técnicos pelas áreas, o projeto de pesquisa foi encaminhado à Comissão Científica do Instituto do Coração, submetido à análise de dois relatores e encaminhado para a Comissão de Ética para Análise de Projetos de Pesquisa (CAPPesq) da Diretoria Clínica do Hospital das Clínicas e da Faculdade de Medicina da Universidade de 
São Paulo. Após a aprovação dessa Comissão (Protocolo 0210/11) foi iniciada a coleta de dados (Anexo 3).

Os pacientes que concordaram em participar da pesquisa assinaram, em duas vias (uma da pesquisadora e a outra do paciente), o Termo de Consentimento Livre e Esclarecido (Anexo1), sendo-Ihes garantido sigilo e anonimato. 
Resultados 


\section{RESULTADOS}

Os resultados são descritos e apresentados em Tabelas e Figuras. São feitas comparações entres os grupos A e B, do ambulatório e do pronto-socorro, respectivamente.

São apresentados os resultados de acordo com o perfil sóciodemográfico; perfil clínico; tempo de conhecimento da doença, internações no último ano; ações de autocuidado. Nesta última categoria de análise, incluímos a adesão ao tratamento, a partir do "Questionário de Aderência em Pacientes com IC".

Ao final, são mostrados os resultados específicos para o grupo B, que incluem o perfil clínico-hemodinâmico, a avaliação e tratamento e os principais desfechos na internação atual. 


\subsection{PERFIL SÓCIO-DEMOGRÁFICO}

Os principais resultados do perfil sócio-demográfico estão demonstrados na Tabela 1.

Tabela 1 - Perfil sócio-demográfico dos pacientes com Insuficiência Cardíaca, Incor, São Paulo - 2011.

\begin{tabular}{|c|c|c|c|c|c|}
\hline Característica & $\begin{array}{c}\text { Grupo A } \\
(n=60)\end{array}$ & $\begin{array}{c}\text { Grupo B } \\
(n=60)\end{array}$ & Todos $(n=120)$ & $\mathbf{p}$ & \\
\hline Idade (anos) & $55,6(8,8)$ & $59,8(13,9)$ & $57,7(11,8)$ & 0,048 & \pm \\
\hline Gênero (masculino) & $41(68)$ & $37(62)$ & $78(65)$ & 0,566 & * \\
\hline Renda (reais) & $1860,3(1056,9)$ & $1168,5(843,04)$ & $1520,4(1014,9)$ & $<0,001$ & \pm \\
\hline Sem renda própria & $0(0)$ & $5(8,8)$ & $5(4,3)$ & 0,026 & * \\
\hline $\begin{array}{l}\text { Situação conjugal } \\
\text { (companheiro) }\end{array}$ & $45(75)$ & $36(60)$ & $81(68)$ & 0,118 & * \\
\hline $\begin{array}{l}\text { Com quem mora (esposo } \\
\text { (a) e filhos) }\end{array}$ & $29(48,4)$ & $20(33,4)$ & $49(40,7)$ & 0,081 & * \\
\hline $\begin{array}{l}\text { Com quem mora } \\
\text { (somente filhos) }\end{array}$ & $9(15)$ & $20(33,3)$ & $29(24,2)$ & 0,081 & * \\
\hline Ocupação (aposentado) & $27(45)$ & $38(63)$ & $65(54,2)$ & 0,002 & * \\
\hline Ocupação (trabalha) & $24(40)$ & $6(10)$ & $30(25)$ & 0,002 & * \\
\hline Escolaridade (1 a 4 anos) & $15(26,3)$ & $20(35,1)$ & $35(30,7)$ & 0,536 & * \\
\hline Escolaridade (5 a 8 anos) & $22(38,6)$ & $16(28,1)$ & $38(33,3)$ & 0,536 & * \\
\hline Religião (católico) & $39(64,9)$ & $32(53,3)$ & $71(59,2)$ & 0,745 & * \\
\hline
\end{tabular}

Nota: Valores expressos como \pm média e desvio padrão a partir do Teste t-student,

* número e porcentagem a partir do Teste exato de Fisher.

Dos 120 entrevistados, 78 (65\%) eram do sexo masculino e 42 (35\%) do sexo feminino. Em relação à situação conjugal, 81 (68\%) relataram ter esposo(a) ou namorado(a) e 39 (32\%) relataram não ter. Houve um menor número de pacientes com companheiro no Grupo B, porém, sem diferença estatisticamente significativa. Grande parte dos pacientes (40,7\%) residia com esposo(a)/namorado(a) e filhos, seguido de pacientes que residiam com os filhos, sem um companheiro (24,2\%) e $16,7 \%$ que residiam apenas com companheiro. Pacientes sem companheiro, residindo apenas com filhos, foram mais frequentes no Grupo B, sem diferença estatisticamente significativa. Além disso, 12(10\%) pacientes moravam 
sozinhos e os demais, $10(8,3 \%)$ com outros parentes (irmãos, pais e sobrinhos).

Quanto à religião, $71(59,2 \%)$ se declararam católicos, seguidos de 31 (25,8\%) evangélicos e 8 (6,7\%) espíritas. A maioria (69\%) se declarou praticante da religião. Não houve diferença estatisticamente significativa do aspecto religioso entre os grupos.

Em relação à escolaridade, $16(13 \%)$ relataram ser analfabetos e $104(87 \%)$ relataram ter frequentado a escola. Destes, a maioria declarou ter estudado de cinco a oito anos, seguidos de pacientes que estudaram de um a quatro anos. Apenas $23(20,2 \%)$ declararam ter de nove a onze anos de estudo e dois (1,8\%), mais de onze anos. Não houve diferença significativa entre os grupos.

Quanto à ocupação, 65 (54,2\%) eram aposentados e 30 (25\%) estavam trabalhando, os demais estavam desempregados ou afastados do trabalho. Houve diferença estatisticamente significativa entre os grupos, visto que 38 (63\% do Grupo B) estavam aposentados, comparado a 27 (45\% do Grupo A). Além disso, apenas seis (10\% do Grupo B) desempenhavam alguma atividade laboral, comparado a 24 (40\% do Grupo A). O número de desempregados e afastados do trabalho também foi maior no Grupo B.

Quanto à renda, houve diferença significativa entre os grupos, com mais indivíduos desprovidos de renda no Grupo B. Não houve diferença no número de dependentes da renda entre os dois grupos. O Teste para comparação entre as médias mostrou diferença estatisticamente significativa em relação à idade e renda, sendo que o Grupo $B$ tinha mais sujeitos idosos e com menor renda, comparado ao Grupo A. 


\subsection{PERFIL CLÍNICO}

Os resultados referentes ao perfil clínico são apresentados nas Tabelas 2, 3, 4, 5, 6 e 7 e na Figura 1.

Tabela 2 - Etiologia da Insuficiência Cardíaca, Incor, São Paulo 2011

\begin{tabular}{lcccccc}
\hline \multirow{2}{*}{ Etiologia } & \multicolumn{2}{c}{ Grupo A } & \multicolumn{2}{c}{ Grupo B } & \multicolumn{2}{c}{ Total } \\
& $\mathbf{n}$ & $\mathbf{\%}$ & $\mathbf{n}$ & $\mathbf{\%}$ & $\mathbf{n}$ & $\%$ \\
\hline Isquêmica & 17 & 28,3 & 16 & 26,7 & 33 & 27,5 \\
Hipertensiva & $\mathbf{2 4}$ & $\mathbf{4 0 , 0}$ & 9 & 15,0 & 33 & 27,5 \\
Chagásica & 9 & 15,0 & $\mathbf{1 8}$ & $\mathbf{3 0 , 0}$ & 27 & 22,5 \\
Idiopática & 9 & 15,0 & 4 & 6,7 & 13 & 10,8 \\
Valvar & 1 & 1,7 & $\mathbf{9}$ & $\mathbf{1 5 , 0}$ & 10 & 8,3 \\
Outras & 0 & 0,0 & 4 & 6,7 & 4 & 3,3 \\
\hline Total & 60 & 100 & 60 & 100 & 120 & 100 \\
\hline
\end{tabular}

Nota: valor do teste exato de Fisher $\mathrm{P}<0,001$.

Conforme dados da Tabela 2, as etiologias mais encontradas foram isquêmica e hipertensiva, seguidas de etiologias chagásica, idiopática e valvar. Sendo que a etiologia hipertensiva foi mais frequente no Grupo A e a etiologia chagásica e valvar mais frequente no Grupo B.

Tabela 3 - Doenças associadas em pacientes com Insuficiência Cardíaca, Incor, São Paulo - 2011

\begin{tabular}{lccccccc}
\hline Doenças associadas & \multicolumn{2}{c}{$\begin{array}{c}\text { Grupo A } \\
(\mathbf{n}=\mathbf{6 0})\end{array}$} & \multicolumn{2}{c}{$\begin{array}{c}\text { Grupo B } \\
(\mathbf{n}=\mathbf{6 0})\end{array}$} & \multicolumn{2}{c}{ Total $(\mathbf{n = 1 2 0})$} & $\mathbf{p}$ \\
& $\mathbf{N}$ & $\mathbf{\%}$ & $\mathbf{N}$ & $\mathbf{\%}$ & $\mathbf{N}$ & $\mathbf{\%}$ & \\
\hline HAS & 50 & 83 & 33 & 55 & 83 & 69 & $\mathbf{0 , 0 0 1}$ \\
DLP & 26 & 43 & 17 & 28 & 43 & 36 & 0,127 \\
Arritmia & 19 & 32 & 23 & 38 & 42 & 35 & 0,566 \\
DAC & 21 & 35 & 15 & 25 & 36 & 30 & 0,319 \\
DM & 11 & 18 & 18 & 30 & 29 & 24 & 0,2 \\
Obesidade & 13 & 22 & 5 & 8,3 & 18 & 15 & $\mathbf{0 , 0 7 1}$ \\
IRC & 8 & 13 & 9 & 15 & 17 & 14 & 1 \\
DCV & 13 & 22 & 3 & 5 & 16 & 13 & $\mathbf{0 , 0 1 4}$ \\
Doença Valvar & 1 & 1,7 & 3 & 5 & 4 & 3,3 & 0,619 \\
DPOC & 1 & 1,7 & 1 & 1,7 & 2 & 1,7 & 1 \\
Neoplasia & 1 & 1,7 & 0 & 0 & 1 & 0,8 & 1 \\
DVP & 1 & 1,7 & 2 & 3,3 & 3 & 2,5 & 1
\end{tabular}


Anemia Desnutrição $0 \quad 0$ Outra

$18 \quad 30 \quad 6$

Nota: P calculado a partir do teste exato de Fischer.

Conforme Tabela 3, a DAC e a dislipidemia (DLP) foram mais frequentes no grupo $A$, porém sem diferença estatisticamente significativa. $A$ HAS, doença cérebro vascular (DCV) e obesidade foram mais frequentes no Grupo A, com diferença estatisticamente significativa entre os grupos. As doenças mais encontradas no Grupo B foram: HAS, arritmia cardíaca, diabetes mellitus (DM), DLP e DAC.

Tabela 4 - Medicamentos usados por pacientes com Insuficiência Cardíaca, Incor, São Paulo - 2011

\begin{tabular}{lccccc}
\hline \multirow{2}{*}{ Medicamento } & \multicolumn{2}{c}{ Grupo A $(\mathbf{n}=\mathbf{6 0})$} & \multicolumn{2}{c}{ Grupo B (n=60) } & p \\
& $\mathbf{n}$ & $\mathbf{\%}$ & $\mathbf{n}$ & $\mathbf{\%}$ & \\
\hline B,bloqueador & 58 & 96,7 & 58 & 96,7 & 0,611 \\
Diurético & 54 & 90 & 53 & 88,3 & 1 \\
IECA & 46 & 76,7 & 33 & 55 & $\mathbf{0 , 0 2 1}$ \\
Espironolactona & 32 & 53,3 & 42 & 70 & 0,091 \\
AAS & 27 & 45 & 17 & 28,3 & 0,088 \\
Digitálico & 18 & 30 & 19 & 31,7 & 1 \\
Anticoagulante & 17 & 28,3 & 21 & 35 & 0,556 \\
Antiarrítmico & 13 & 21,7 & 19 & 31,7 & 0,302 \\
Vasodilatador & 10 & 16,7 & 24 & 40 & $\mathbf{0 , 0 0 8}$ \\
\hline Notailar
\end{tabular}

Nota: P calculado a partir do teste de Qui-Quadrado de Pearson.

Conforme dados da Tabela 4, houve maior frequência de vasodilatadores no Grupo B e de inibidores da enzima conversora de angiotensina (IECA) no Grupo A. Para os demais medicamentos não houve diferença estatisticamente significativa.

Tabela 5 - Classe funcional conforme classificação da "New York Heart Association" (NYHA) em pacientes com Insuficiência Cardíaca, Incor, São Paulo - 2011

\begin{tabular}{lcccccc}
\hline \multirow{2}{*}{ Classe funcional } & \multicolumn{2}{c}{ Grupo A } & \multicolumn{2}{c}{ Grupo B } & \multicolumn{2}{c}{ Total } \\
& $\mathbf{n}$ & $\%$ & $\mathbf{n}$ & $\%$ & $\mathbf{n}$ & $\%$ \\
\hline I & 27 & 44,9 & 0 & 0 & 27 & 22 \\
II & 25 & 41,7 & 3 & 5 & 28 & 23
\end{tabular}




\begin{tabular}{lrrrrrr} 
III & 7 & 11,7 & 32 & 53 & 39 & 32 \\
IV & 1 & 1,7 & 25 & 42 & 26 & 22 \\
\hline Total & $\mathbf{6 0}$ & $\mathbf{1 0 0}$ & $\mathbf{6 0}$ & $\mathbf{1 0 0}$ & $\mathbf{1 2 0}$ & $\mathbf{1 0 0}$ \\
\hline
\end{tabular}

Nota: Valor do teste exato de Fisher $\mathrm{P}<0,001$.

Conforme Tabela 5, em relação à classe funcional, houve diferença estatisticamente significativa entre os grupos, pois 52 pacientes (86,6\% do Grupo A) estavam entre classes I e II e 57 pacientes (95\% do Grupo B) estavam entre classes III e IV.

Tabela 6- Valores de fração de ejeção, diâmetro sistólico e diâmetro diastólico dos pacientes com Insuficiência Cardíaca, Incor, São Paulo - 2011

\begin{tabular}{llccc}
\hline Variável & \multicolumn{1}{c}{ Grupo } & $\mathbf{n}$ & Valores & $\mathbf{p}$ \\
\hline \multirow{2}{*}{ FEVE $(\%)$} & Todos & $\mathbf{1 1 9}$ & $\mathbf{3 0 , 9}(\mathbf{9}, \mathbf{9})$ & \\
& Grupo A & 59 & $32,6(9,4)$ & $\mathbf{0 , 0 6 9}$ \\
& GrupoB & 60 & $29,3(10,2)$ & \\
& Todos & $\mathbf{1 1 5}$ & $\mathbf{5 4 , 5 ( 1 0 , 3 )}$ & \\
DS $(\mathrm{mm})$ & Grupo A & 57 & $54,1(9,1)$ & $\mathbf{0 , 6 6 5}$ \\
& GrupoB & 58 & $54,9(11,5)$ & \\
& & & & \\
DD $(\mathrm{mm})$ & Todos & $\mathbf{1 1 5}$ & $\mathbf{6 4 , 1}(\mathbf{9}, 4)$ & $\mathbf{0 , 6 2 3}$ \\
& Grupo A & 57 & $64,6(8,3)$ & \\
\hline
\end{tabular}

Nota: Valores expressos em média e desvio padrão. Comparação entre as médias a partir do teste t de Sudent.

Conforme Tabela 6, a estatística descritiva não demonstrou diferença significativa na fração de ejeção do ventrículo esquerdo (FEVE), diâmetro sistólico (DS) e diâmetro diastólico (DD) entre os grupos.

A análise descritiva da FEVE por etiologia mostrou uma média de $30,941( \pm 9,924)$. As variações por etiologia estão demonstradas na Figura 1. 


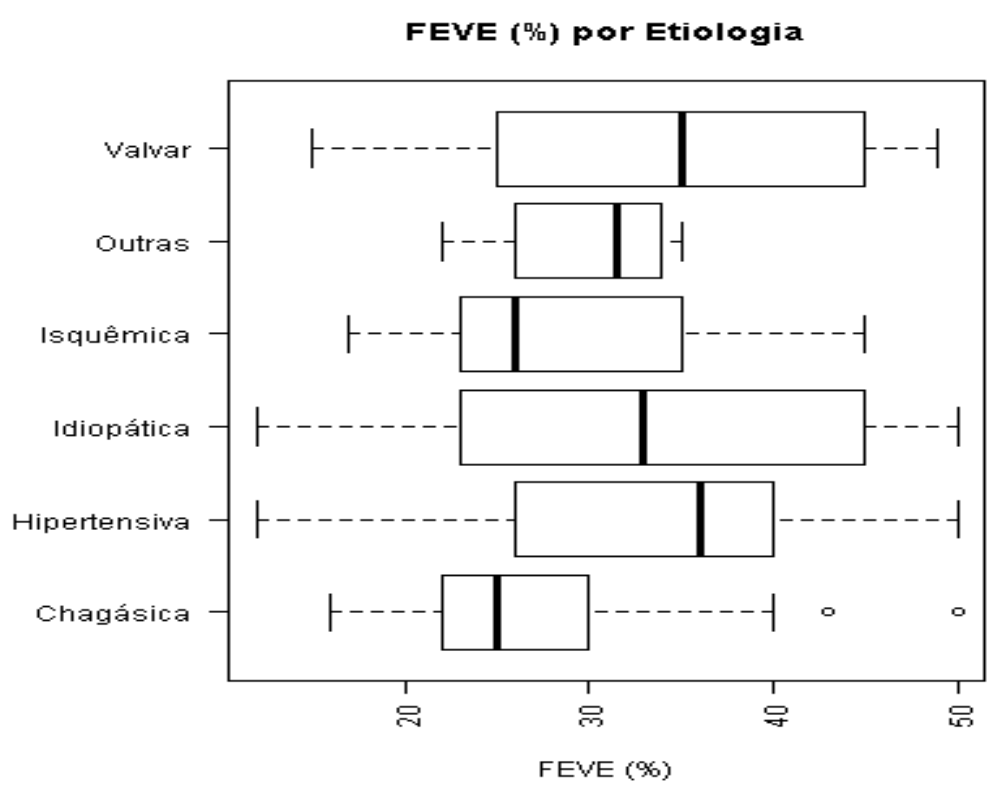

Nota: Análise descritiva a partir do teste ANOVA, P 0,147.

Figura 1 - FEVE por Etiologia em pacientes com Insuficiência Cardíaca, Incor, São Paulo - 2011.

A associação entre a classe funcional e a etiologia mostrou que $27(100 \%)$ dos pacientes com etiologia chagásica e $9(90 \%)$ dos pacientes com etiologia valvar estavam em classe funcional III a IV, 21 (63,6\%) dos pacientes com etiologia hipertensiva estavam em classe funcional I e II. Os pacientes com etiologia isquêmica estavam em classe funcional I a IV, isto é, distribuídos de maneira uniforme. 
Tabela 7 - Valores de exames laboratoriais dos pacientes com Insuficiência Cardíaca, Incor, São Paulo - 2011

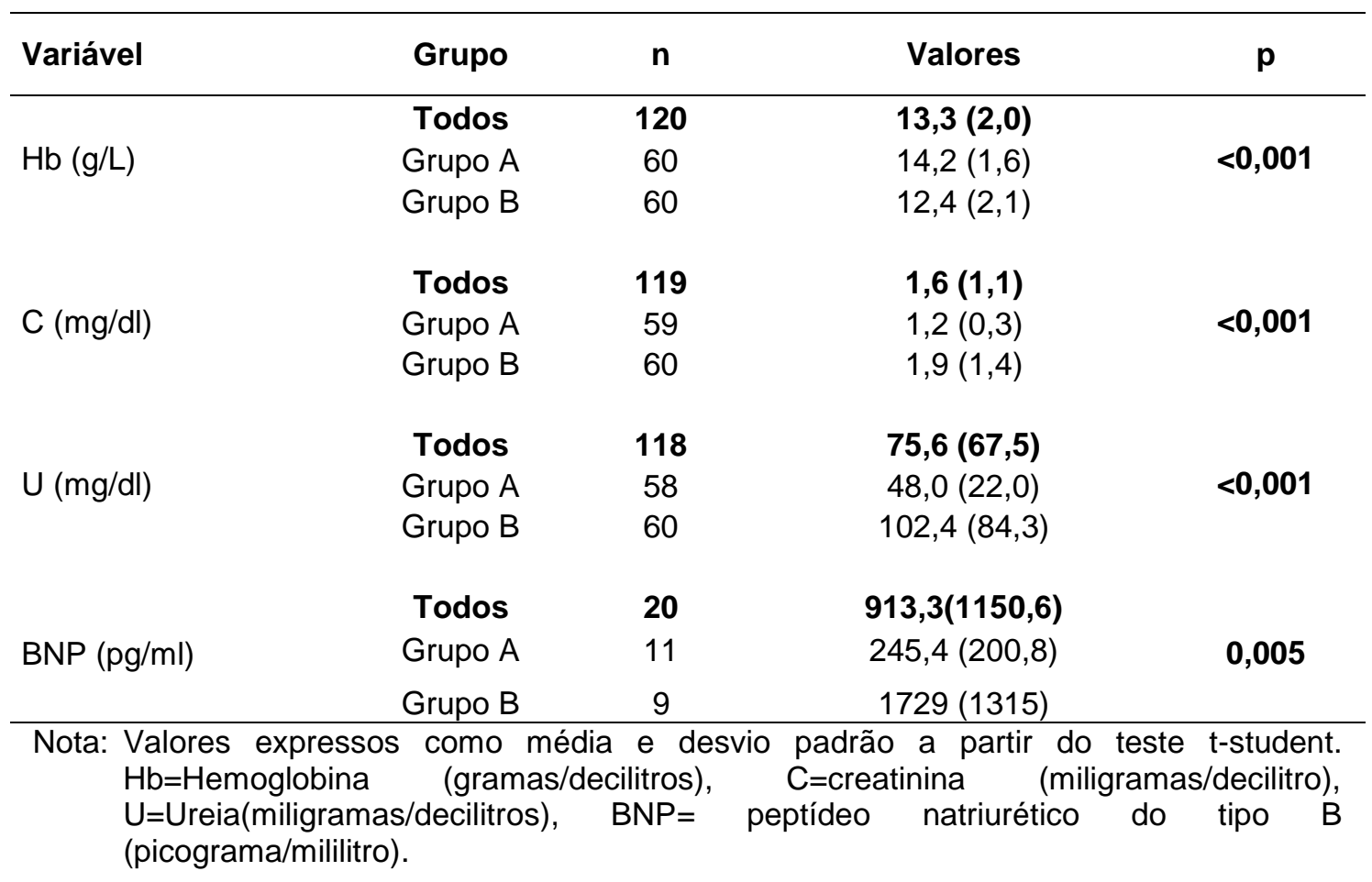

Conforme Tabela 7, os pacientes do Grupo B tiveram piores resultados de função renal (uréia e creatinina) e hemoglobina. Os resultados de BNP também foram piores no Grupo B, embora tenha sido encontrado em apenas 20 pacientes.

Os dispositivos implantados, como stent de coronária, prótese valvar, marcapasso e cardiodesfibrilador, foram mais encontrados no Grupo $B$, porém, sem diferença estatisticamente significativa.

\subsection{TEMPO DE CONHECIMENTO SOBRE A DOENÇA E INTERNAÇÕES NO ÚLTIMO ANO}

A análise descritiva do tempo de conhecimento sobre a doença demonstrou uma média de 9,392 anos $( \pm 8,061)$ sem diferença entre os 
grupos. Não houve associação entre o tempo de conhecimento sobre a doença e a ocorrência de internações no último ano, conforme Figura 2.

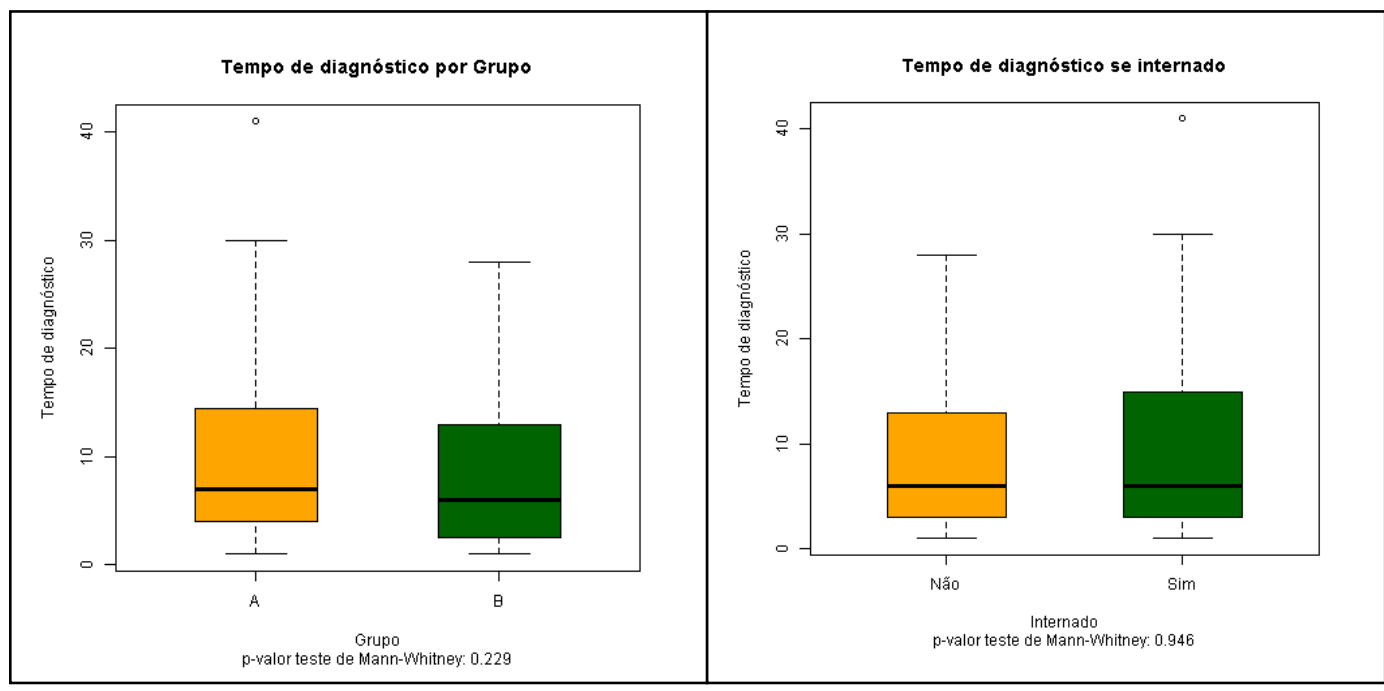

Figura 2 - Tempo de conhecimento sobre a doença por grupo e associação com ocorrência de internação no último ano em pacientes com Insuficiência Cardíaca, Incor, São Paulo - 2011.

Tabela 8 - Ocorrência de internações não planejadas no último ano em pacientes com Insuficiência Cardíaca, Incor, São Paulo - 2011

\begin{tabular}{lcccccc}
\hline \multirow{2}{*}{ № de internações } & \multicolumn{2}{c}{ Grupo A } & \multicolumn{2}{c}{ Grupo B } & \multicolumn{2}{c}{ Total } \\
& $\mathbf{n}$ & $\%$ & $\mathbf{n}$ & $\%$ & $\mathbf{n}$ & $\%$ \\
\hline Nenhuma vez & 40 & 66,7 & 7 & 12,0 & 47 & 39,0 \\
1 vez & 11 & 18,4 & 12 & 20,0 & 23 & 19,0 \\
2 vezes & 5 & 8,3 & 14 & 23,0 & 19 & 16,0 \\
3 vezes & 2 & 3,3 & 11 & 18,0 & 13 & 11,0 \\
4 ou mais & 2 & 3,3 & 16 & 27,0 & 18 & 15,0 \\
\hline Total & 60 & 100,0 & 60 & 100,0 & 120 & 100,0 \\
\hline
\end{tabular}

Nota: Valor do teste exato de Fisher $<0,001$.

Conforme pode ser observado na Tabela 8 , houve diferença estatisticamente significativa na ocorrência e número de internações não 
planejadas no último ano entre os grupos. Além disso, dos 53 (88\%) pacientes que relataram ter buscado o serviço de emergência ou permanecido internado no Grupo B, 16 (26,6\%) experimentaram quatro ou mais internações.

Tabela 9 - Ocorrência de internações não planejadas no último ano de acordo com a etiologia em pacientes com Insuficiência Cardíaca, Incor, São Paulo - 2011

\begin{tabular}{lcccccc}
\hline \multirow{2}{*}{ Etiologia } & \multicolumn{2}{c}{ Não } & \multicolumn{2}{c}{ Internado } & \multicolumn{2}{c}{ Total } \\
& $\mathbf{n}$ & $\%$ & $\mathbf{n}$ & $\%$ & $\mathbf{n}$ & $\%$ \\
\hline Isquêmica & 11 & 33,3 & 22 & 66,7 & 33 & 100 \\
Hipertensiva & 17 & 51,5 & 16 & 48,5 & 33 & 100 \\
Chagásica & 6 & 22,2 & $\mathbf{2 1}$ & $\mathbf{7 7 , 8}$ & 27 & 100 \\
Idiopática & $\mathbf{1 0}$ & $\mathbf{7 6 , 9}$ & 3 & 23,1 & 13 & 100 \\
Valvar & 1 & 10,0 & $\mathbf{9}$ & $\mathbf{9 0 , 0}$ & 10 & 100 \\
Outras & 1 & 25,0 & 3 & 75,0 & 4 & 100 \\
\hline Total & 46 & 38,3 & 74 & 61,7 & 120 & 100 \\
\hline Nota: Valor do teste exato de Fisher $<0,002$ & & & &
\end{tabular}

Conforme mostra a Tabela 9, houve maior ocorrência de internações não planejadas no último ano em pacientes com etiologia chagásica e valvar e menor ocorrência em pacientes com etiologia idiopática.

\subsection{AÇÕES DE AUTOCUIDADO ESPECÍFICAS EM PESSOAS COM INSUFICIÊNCIA CARDÍACA EM CLÍNICA ESPECIALIZADA E PRONTO-SOCORRO}

Conforme mencionado na revisão da literatura deste estudo, as ações de autocuidado incluem o cumprimento e a adesão ao tratamento farmacológico e não farmacológico, no que se relaciona à adequação da dieta e de líquidos, ao peso diário, à imunização, ao monitoramento dos sintomas de piora clínica, além da busca por ajuda, quando os sintomas ocorrem ${ }^{51}$. 
$A$ adesão às orientações para 0 tratamento correto da IC depende, em grande parte, do conhecimento e compreensão destas orientações, por parte dos pacientes e de seus familiares. Somados a isso, é necessário que o paciente faça o julgamento correto para monitorizar os sintomas de piora da IC, que é uma síndrome passível de frequentes descompensações. Depende ainda, do conhecimento e habilidade dos pacientes para manter estes comportamentos. $O$ conjunto de todas estas ações é denominado de autocuidado ${ }^{52}$.

As ações de autocuidado específicas em pessoas com insuficiência cardíaca em clínica especializada (Grupo A) e pronto-socorro (Grupo B), assim como a diferença entre o autocuidado nesses grupos são apresentadas nos resultados a seguir.

Tabela 10 - Hábitos sobre o controle de peso em pacientes com Insuficiência Cardíaca, Incor, São Paulo - 2011

\begin{tabular}{|c|c|c|c|c|c|c|c|}
\hline \multirow{2}{*}{$\begin{array}{l}\text { Facilidade } \\
\text { para se } \\
\text { pesar }\end{array}$} & \multicolumn{2}{|c|}{ Grupo A } & \multicolumn{2}{|c|}{ Grupo B } & \multicolumn{2}{|c|}{ Total } & \multirow[b]{2}{*}{$\mathbf{p}$} \\
\hline & $\mathbf{n}$ & $\%$ & $\mathbf{n}$ & $\%$ & $\mathbf{N}$ & $\%$ & \\
\hline Sim & 56 & 93,3 & 51 & 85,0 & 107 & 89,0 & 0,239 \\
\hline Não & 4 & 6,7 & 9 & 15,0 & 13 & 11,0 & \\
\hline Total & 60 & 100,0 & 60 & 100,0 & 120 & 100,0 & \\
\hline \multirow{2}{*}{$\begin{array}{l}\text { Dificuldade } \\
\text { para se } \\
\text { pesar }\end{array}$} & \multicolumn{2}{|c|}{ Grupo A } & \multicolumn{2}{|c|}{ Grupo B } & \multicolumn{2}{|c|}{ Total } & $\mathbf{p}$ \\
\hline & $\mathbf{n}$ & $\%$ & $\mathbf{n}$ & $\%$ & $\mathbf{n}$ & $\%$ & 0,036 \\
\hline Cansaço & 1 & 25,0 & 5 & 62,5 & 6 & 50,0 & \\
\hline Locomoção & 0 & 0,0 & 3 & 37,5 & 3 & 25,0 & \\
\hline Distância & 3 & 75,0 & 0 & 0,0 & 3 & 25,0 & \\
\hline Não informou & 0 & - & 1 & - & 1 & - & \\
\hline Total & 4 & 100,0 & 9 & 100,0 & 13 & 100,0 & \\
\hline \multicolumn{8}{|c|}{ Nota: P calculado a partir do teste exato de Fisher. } \\
\hline \multicolumn{8}{|c|}{$\begin{array}{l}\text { Em relação ao controle de peso, apresentado na Tabela 10, a } \\
\text { os pacientes mencionou ter facilidade para se pesar regularmente. }\end{array}$} \\
\hline \multicolumn{8}{|c|}{$\begin{array}{l}\text { Dos pacientes que relataram dificuldade, a maioria atribuiu ao cansaço, } \\
\text { sequido de dificuldade de deambulação e distância de casa até a balança, }\end{array}$} \\
\hline
\end{tabular}


habituados a se pesar em drogarias, 14 (12\%) em postos de saúde e apenas $9(7,7 \%)$ relataram ter balança em casa.

Em relação à percepção de piora clínica e procura pela equipe de saúde, os pacientes explicitaram sobre aumento recente de peso, falta de ar e edema de membros inferiores, conforme Tabela 11, 12 e 13.

Tabela 11 - Percepção do aumento de peso e procura pela equipe de saúde em pacientes com Insuficiência Cardíaca, Incor, São Paulo - 2011

\begin{tabular}{|c|c|c|c|c|c|c|c|}
\hline \multirow{2}{*}{$\begin{array}{l}\text { Avisa se } \\
\text { aumento de } \\
\text { peso }\end{array}$} & \multicolumn{2}{|c|}{ Grupo A } & \multicolumn{2}{|c|}{ Grupo B } & \multicolumn{2}{|c|}{ Total } & \multirow[t]{2}{*}{$p$} \\
\hline & $\mathbf{n}$ & $\%$ & $\mathbf{n}$ & $\%$ & $\mathbf{n}$ & $\%$ & \\
\hline Sim & 31 & 54,4 & 39 & 65,0 & 70 & 59,8 & 0,263 \\
\hline Não & 26 & 45,6 & 21 & 35,0 & 47 & 40,2 & \\
\hline Não & & & & & & & \\
\hline informou & 3 & - & 0 & - & 3 & - & \\
\hline Total & 60 & 100,0 & 60 & 100,0 & 120 & 100,0 & \\
\hline $\begin{array}{l}\text { Não avisa } \\
\text { O que faz }\end{array}$ & & & & & & & 0,142 \\
\hline Aumenta o & & & & & & & \\
\hline Diurético & 8 & 33,3 & 10 & 47,6 & 18 & 40,0 & \\
\hline $\begin{array}{l}\text { Aguarda } \\
\text { Reduz }\end{array}$ & 6 & 25,0 & 9 & 42,9 & 15 & 33,3 & \\
\hline líquido & 5 & 20,8 & 1 & 4,8 & 6 & 13,3 & \\
\hline Muda a dieta & 3 & 12,5 & 0 & 0,0 & 3 & 6,7 & \\
\hline Reduz sal & 1 & 4,2 & 1 & 4,8 & 2 & 4,4 & \\
\hline Toma chá & 1 & 4,2 & 0 & 0,0 & 1 & 2,2 & \\
\hline Total & 26 & 100,0 & 21 & 100,0 & 47 & 100,0 & \\
\hline
\end{tabular}

Nota: P a partir do teste exato de Fisher.

Conforme Tabela 11, a maioria dos pacientes informou que avisa o médico ou o enfermeiro em caso de aumento recente de peso. Dos pacientes que informaram não avisar a equipe de saúde, as atitudes mais citadas foram: manejo de diurético, espera pela melhora espontânea, redução de líquidos ingeridos diariamente, redução de alimentos ingeridos diariamente, redução do sal da dieta e ingestão de chás. 
Tabela 12 - Percepção da falta de ar e procura pela equipe de saúde em pacientes com Insuficiência Cardíaca, Incor, São Paulo - 2011

\begin{tabular}{|c|c|c|c|c|c|c|c|}
\hline \multirow{2}{*}{$\begin{array}{l}\text { Avisa se } \\
\text { falta de ar }\end{array}$} & \multicolumn{2}{|c|}{ Grupo A } & \multicolumn{2}{|c|}{ Grupo B } & \multicolumn{2}{|c|}{ Total } & \multirow[t]{2}{*}{$\mathbf{p}$} \\
\hline & $n$ & $\%$ & $\mathbf{n}$ & $\%$ & $\mathbf{n}$ & $\%$ & \\
\hline$\overline{\text { Sim }}$ & 49 & 82,0 & 56 & 93,3 & 105 & 88,0 & 0,095 \\
\hline Não & 11 & 18,0 & 4 & 6,7 & 15 & 12,0 & \\
\hline Total & 60 & 100,0 & 60 & 100,0 & 120 & 100,0 & \\
\hline $\begin{array}{l}\text { Não avisa } \\
\text { O que faz }\end{array}$ & & & & & & & 0,082 \\
\hline $\begin{array}{l}\text { Descansa } \\
\text { Aumenta o }\end{array}$ & 5 & 55,5 & 2 & 33,3 & 7 & 46,6 & \\
\hline Diurético & 2 & 22,3 & 3 & 50,0 & 5 & 33,4 & \\
\hline $\begin{array}{l}\text { Faz Inalação } \\
\text { Reduz }\end{array}$ & 1 & 11,1 & 1 & 16,7 & 2 & 13,3 & \\
\hline líquido & 1 & 11,1 & 0 & 0,0 & 1 & 6,7 & \\
\hline Total & 9 & 100,0 & 6 & 100,0 & 15 & 100,0 & \\
\hline
\end{tabular}

Nota: $\mathrm{P}$ a partir do teste exato de Fisher.

Conforme a Tabela 12, 105 (88\%) pacientes relataram que avisam o médico ou enfermeiro em caso de piora da falta de ar. Os pacientes que informaram não avisar a equipe de saúde adotaram as seguintes condutas: descanso, manejo do diurético, inalação e redução de líquidos. 
Tabela 13 - Percepção do edema periférico e procura pela equipe de saúde em pacientes com Insuficiência Cardíaca, Incor, São Paulo - 2011

\begin{tabular}{|c|c|c|c|c|c|c|c|}
\hline \multirow{2}{*}{$\begin{array}{l}\text { Avisa se } \\
\text { edema }\end{array}$} & \multicolumn{2}{|c|}{ Grupo A } & \multicolumn{2}{|c|}{ Grupo B } & \multicolumn{2}{|c|}{ Total } & \multirow[t]{2}{*}{$p$} \\
\hline & $\mathbf{n}$ & $\%$ & $\mathbf{n}$ & $\%$ & $\mathbf{n}$ & $\%$ & \\
\hline Sim & 34 & 60,0 & 40 & 66,7 & 74 & 63,3 & 0,447 \\
\hline Não & 24 & 40,0 & 20 & 33,3 & 44 & 36,7 & \\
\hline \multicolumn{8}{|l|}{ Não } \\
\hline informou & 2 & - & 0 & - & 2 & - & \\
\hline Total & 60 & 100,0 & 60 & 100,0 & 120 & 100,0 & \\
\hline \multicolumn{8}{|l|}{ Não avisa } \\
\hline O que faz & & & & & & & 0,682 \\
\hline \multicolumn{8}{|l|}{ Aumenta o } \\
\hline Diurético & 7 & 30,4 & 14 & 66,7 & 21 & 47,7 & \\
\hline Aguarda & 6 & 26,0 & 3 & 14,3 & 9 & 20,4 & \\
\hline Eleva MMII & 3 & 13,0 & 2 & 9,5 & 5 & 11,4 & \\
\hline Reduz & & & & & & & \\
\hline líquido & 4 & 17,4 & 1 & 4,8 & 5 & 11,4 & \\
\hline Reduz sal & 2 & 8,7 & 1 & 4,8 & 3 & 6,8 & \\
\hline Toma chá & 1 & 4,3 & 0 & 0,0 & 1 & 2,3 & \\
\hline Total & 23 & 100,0 & 21 & 100,0 & 44 & 100,0 & \\
\hline
\end{tabular}

Nota: $\mathrm{P}$ a partir do teste exato de Fisher.

Conforme a Tabela 13, a maioria dos pacientes relatou que avisam o médico ou enfermeiro, em caso de piora do edema periférico, sendo a maior parte no Grupo B. Entre os pacientes que informaram não avisar a equipe de saúde, as atitudes mais frequentemente adotadas foram: manejo do diurético, elevação de membros inferiores e redução de líquidos, espera pela melhora espontânea, redução de sal, repouso e uso de chás.

Embora não tenha diferença estatisticamente significativa entre os grupos, o Grupo B demonstrou estar mais orientado a manejar o diurético em casos de piora clínica. Em contrapartida, o Grupo A demonstrou estar mais orientado a reduzir o líquido e o sal da dieta.

Os resultados sobre vacinação anual contra influenza podem ser vistos na Tabela 14. 
Tabela 14 - Vacinação anual contra influenza em pacientes com Insuficiência Cardíaca, Incor, São Paulo - 2011

\begin{tabular}{lccccccc}
\hline \multirow{2}{*}{ Vacina } & \multicolumn{2}{c}{ Grupo A } & \multicolumn{2}{c}{ Grupo B } & \multicolumn{2}{c}{ Total } & p \\
& $\mathbf{n}$ & $\%$ & $\mathbf{n}$ & $\%$ & $\mathbf{n}$ & $\%$ & \\
\hline Sim & 29 & 48,3 & 25 & 42,4 & 54 & 45,4 & $\mathbf{0 , 5 8 2}$ \\
Não & 31 & 51,7 & 34 & 57,6 & 65 & 54,6 & \\
Não informou & 0 & - & 1 & - & 1 & - & \\
Total & 60 & 100,0 & 60 & 100,0 & 120 & 100,0 &
\end{tabular}

Sem vacina

Motivo

Não sabia

Medo

16

55,2

13,8

Esqueceu

13,8

Quadro gripal

6,9

Não acredita

0,0

Acesso

3,4

Cirurgia

0,0

Dor

Locomoção

3,4

Total

3,4

Nota: $\mathrm{P}$ a partir do teste exato de Fisher.

\begin{tabular}{ccccc}
$\mathbf{1 5}$ & $\mathbf{4 6 , 9}$ & $\mathbf{3 1}$ & $\mathbf{5 0 , 8}$ & $\mathbf{0 , 2 2 7}$ \\
4 & 12,5 & 8 & 13,1 & \\
3 & 9,4 & 7 & 11,5 & \\
4 & 12,5 & 6 & 9,8 & \\
5 & 15,6 & 5 & 8,2 & \\
0 & 0,0 & 1 & 1,6 & \\
1 & 3,1 & 1 & 1,6 & \\
0 & 0,0 & 1 & 1,6 & \\
0 & 0,0 & 1 & 1,6 & \\
$\mathbf{3 4}$ & $\mathbf{1 0 0 , 0}$ & $\mathbf{6 5}$ & $\mathbf{1 0 0 , 0}$ & \\
\hline
\end{tabular}

Conforme a Tabela 14, a minoria dos pacientes afirmou ter vacinação atualizada contra gripe. Grande parte dos pacientes que não receberam a última vacina, explicaram que não haviam recebido orientação do médico ou enfermeiro. Os demais disseram que tinham medo da reação, haviam esquecido, apresentavam quadro gripal na época da vacinação, não acreditavam no efeito benéfico da vacinação e os demais atribuíram à dificuldade de acesso e dor da aplicação. Houve pior resultado no Grupo B, porém não foi estatisticamente significativo, conforme Tabela 14.

$\mathrm{Na}$ Tabela 15 são apresentadas as orientações sobre a restrição de líquido e o controle de peso nos pacientes dos Grupos A e B. 
Tabela 15 - Orientação sobre restrição de líquidos e controle de peso diário em pacientes com Insuficiência Cardíaca, Incor, São Paulo - 2011

\begin{tabular}{|c|c|c|c|c|c|c|c|}
\hline \multirow{2}{*}{$\begin{array}{l}\text { Limite de } \\
\text { líquido/dia } \\
\text { (ml) }\end{array}$} & \multicolumn{2}{|c|}{ Grupo A } & \multicolumn{2}{|c|}{ Grupo B } & \multicolumn{2}{|c|}{ Total } & \multirow[t]{2}{*}{$\mathbf{p}$} \\
\hline & $n$ & $\%$ & $\mathbf{n}$ & $\%$ & $n$ & $\%$ & \\
\hline 400 a 900 & 2 & 4,6 & 12 & 22,1 & 14 & 14,4 & \\
\hline 1000 & 21 & 48,8 & 34 & 63,0 & 55 & 56,7 & \\
\hline 1200 & 3 & 7,0 & 3 & 5,6 & 6 & 6,2 & \\
\hline 1500 & 14 & 32,6 & 3 & 5,6 & 17 & 17,5 & \\
\hline 2000 & 3 & 7,0 & 2 & 3,7 & 5 & 5,2 & \\
\hline Total & 43 & 100 & 54 & 100 & 97 & 100 & \\
\hline $\begin{array}{l}\text { Orientado a } \\
\text { restringir } \\
\text { líquidos }\end{array}$ & & & & & & & 0,76 \\
\hline Não & 6 & 12,2 & 6 & 10,0 & 12 & 11,0 & \\
\hline Não informou & 11 & - & 0 & - & 11 & - & \\
\hline Total & 60 & 100 & 60 & 100 & 120 & 100 & \\
\hline $\begin{array}{l}\text { Orientado a } \\
\text { controlar o } \\
\text { peso }\end{array}$ & & & & & & & 0,001 \\
\hline Não & 57 & 95 & 30 & 50 & 87 & 72 & \\
\hline Sim & 3 & 5 & 30 & 50 & 33 & 28 & \\
\hline Total & 60 & 100 & 60 & 100 & 120 & 100 & \\
\hline
\end{tabular}

Nota: $\mathrm{P}$ a partir do teste exato de Fisher.

Conforme a Tabela 15, os pacientes estavam bem orientados sobre a restrição de líquidos, sendo que a maioria estava orientada a ingerir de $1000 \mathrm{ml}$ a $1500 \mathrm{ml} /$ dia. A maioria informou não ter recebido orientação sobre o controle de peso diário. Houve diferença entre os grupos, com melhor orientação no Grupo B.

\subsubsection{Adesão ao tratamento em pacientes com Insuficiência Cardíaca}

A consistência interna do "Questionário de aderência em pacientes com IC" foi avaliada por meio do alfa de Cronbach $(\alpha=0,69)$, indicando que as questões eram consistentes entre si. 
A Figura 3 mostra o Escore total do "Questionário de Aderência em pacientes com IC".

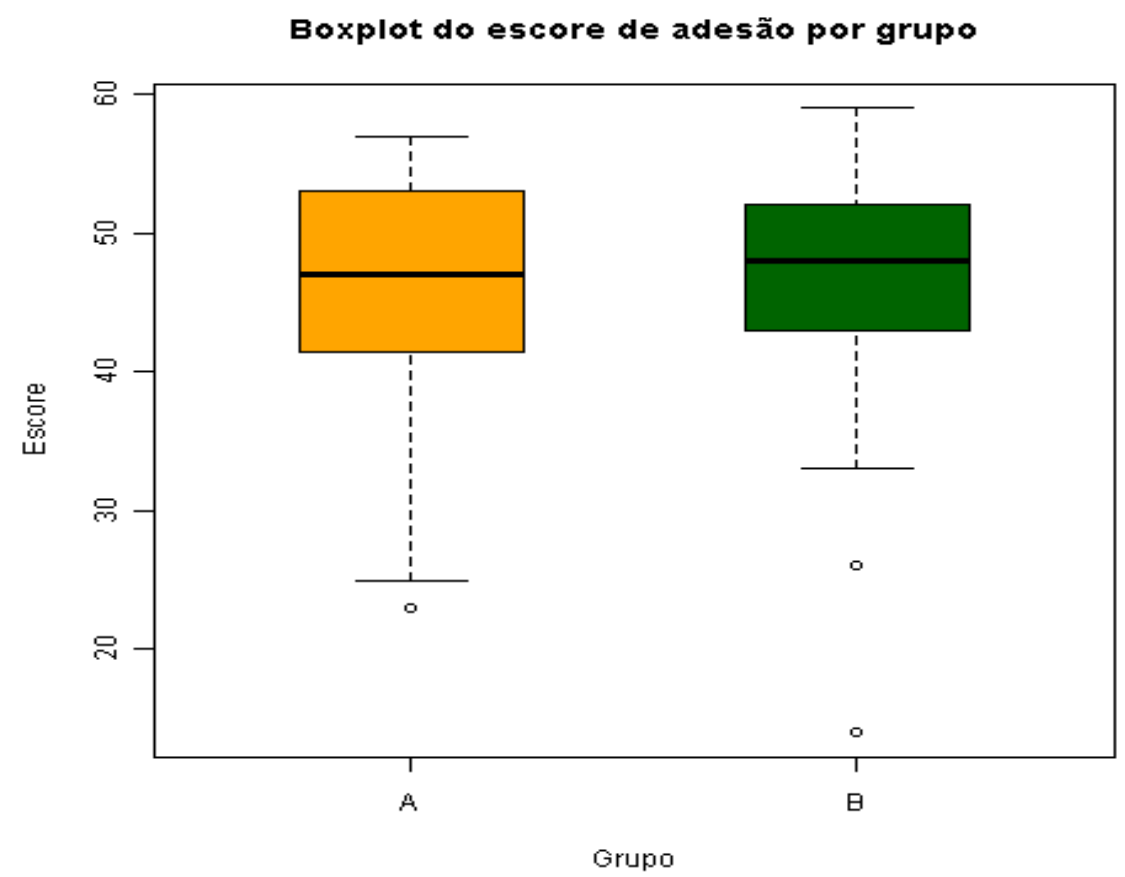

Nota: $\mathrm{P}$ a partir do Teste T-student $=0,726$.

Figura 3 - Escore total do "Questionário de Aderência em pacientes com Insuficiência Cardíaca", Incor, São Paulo $-2011$

Não houve diferença estatisticamente significativa no escore total de adesão entre os grupos, com média $46,09( \pm 8,03)$, sendo $45,83( \pm 8,14)$ no Grupo A e 46,35( $\pm 7,97)$ no Grupo B (figura 3).

Quando analisados separadamente, apenas os itens 4 e 9 do instrumento, relacionados à adição de temperos, molhos e alimentos industrializados nas refeições e consumo de bebida alcoólica, tiveram diferença estatisticamente significativa, com melhor escore no Grupo B, conforme a Tabela 16. 
Tabela 16 - Escore por questão do "Questionário de Aderência em pacientes com Insuficiência Cardíaca", Incor, São Paulo $-2011$

\begin{tabular}{|c|c|c|c|c|}
\hline & Questão & $\begin{array}{c}\text { Grupo A } \\
(n=60)^{*}\end{array}$ & $\begin{array}{c}\text { Grupo B } \\
(n=60)^{*}\end{array}$ & $\mathbf{p}^{\star *}$ \\
\hline 01 & $\begin{array}{l}\text { Toma regularmente os medicamentos de acordo } \\
\text { com a prescrição? }\end{array}$ & $5,58(1,01)$ & $5,23(1,59)$ & 0,312 \\
\hline 02 & Tem se pesado diariamente? & $0,87(0,96)$ & $0,88(1,49)$ & 0,131 \\
\hline 03 & Restringe adição de sal nos alimentos? & $5,28(1,30)$ & $5,18(1,54)$ & 0,732 \\
\hline 04 & $\begin{array}{l}\text { Adiciona tempero, molhos e outros alimentos } \\
\text { industrializados com sal em suas refeições? }\end{array}$ & $4,92(1,80)$ & $5,67(0,80)$ & 0,005 \\
\hline 05 & $\begin{array}{l}\text { Tem se alimentado fora de casa sem restringir o } \\
\text { sal? }\end{array}$ & $5,13(1,24)$ & $5,30(1,25)$ & 0,167 \\
\hline 06 & $\begin{array}{l}\text { Tem consumido em suas refeições sopas, } \\
\text { gelatinas, sorvetes, sucos, leites, chás, cafés, } \\
\text { refrigerantes, etc. sem considerar a quantidade } \\
\text { de líquido? }\end{array}$ & $4,15(2,31)$ & $4,00(2,38)$ & 0,708 \\
\hline 07 & $\begin{array}{l}\text { Restringe a ingestão de líquidos de acordo com } \\
\text { a orientação do médico ou da enfermeira? }\end{array}$ & $4,50(1,80)$ & $4,30(1,94)$ & 0,67 \\
\hline 08 & $\begin{array}{l}\text { Ingere frutas com alto teor de líquido, tais como } \\
\text { laranja, melão, melancia, abacaxi, água do côco, } \\
\text { etc, sem considerar o líquido? }\end{array}$ & $3,80(2,36)$ & $4,22(1,95)$ & 0,446 \\
\hline 09 & Ingere alguma bebida alcoólica? & $5,65(0,82)$ & $5,82(0,85)$ & 0,038 \\
\hline 10 & $\begin{array}{l}\text { Você faltou em alguma consulta médica, de } \\
\text { enfermagem ou exames programados? }\end{array}$ & $5,95(0,22)$ & $5,75(1,10)$ & 0,448 \\
\hline
\end{tabular}

Nota: *Valores expressos em média e desvio padrão. ${ }^{*} \mathrm{P}$ obtido a partir do Teste de MannWhitney para comparação de escalas.

Os resultados apresentados na Tabela 16 demonstram não haver diferenças significativas na adesão ao tratamento entre os grupos.

Em contrapartida, encontramos diferenças no perfil sociodemográfico, devido à maioria de idosos, sem renda e aposentados no Grupo B; diferenças no perfil clínico evidenciadas por piores níveis de ureia, creatinina, hemoglobina, além de mais chagásicos, pacientes em classe funcional III e IV, com arritmia e portadores de MPD.

O fato de não haver diferença significativa na adesão ao tratamento e em ações específicas de autocuidado, a constatação de aspectos que demonstram pior perfil no Grupo B, nos conduziram a elaborar 
a hipótese de que a principal causa de internação atual e história de internações não planejadas no último ano no Grupo B estariam relacionadas à gravidade e à fase avançada da IC. Diante disso, incluímos a descrição de dados específicos para pacientes com ICD nos resultados do Grupo B.

\subsection{PERFIL DE PACIENTES COM INSUFICIÊNCIA CARDÍACA DESCOMPENSADA}

Os dados relativos ao perfil hemodinâmico, avaliação, tratamento e desfechos da internação hospitalar do Grupo B são demonstrados nas Tabelas 17, 18 e 19.

Tabela 17 - Perfil hemodinâmico em pacientes com Insuficiência Cardíaca descompensada, Incor, São Paulo - 2011.

\begin{tabular}{lcc}
\hline Perfil hemodinâmico & G & Grupo B \\
\hline A - Quente/seco & 1 & $\%$ \\
B - Quente/úmido & 22 & 1,6 \\
C - Frio/úmido & 22 & 36,7 \\
D - Frio/seco & 15 & 36,7 \\
\hline Total & $\mathbf{6 0}$ & 25 \\
\hline
\end{tabular}

Dos 60 pacientes do Grupo B, 44 (73,4\%) tinham sinais de congestão (Perfil B e C). Destes, 22 (50\%) apresentavam sinais de baixo débito cardíaco (Perfil C). Pacientes com baixo débito cardíaco (Perfil C e D) totalizaram $37(61,7 \%)$.

A Tabela 18 mostra a avaliação e tratamento dos pacientes com IC descompensada. 
Tabela 18 - Avaliação e tratamento em pacientes com Insuficiência Cardíaca descompensada, Incor, São Paulo - 2011

\begin{tabular}{lcc}
\hline Avaliação e tratamento & $\mathbf{n}$ & Grupo B (n=60) \\
\hline Exames & 58 & $\%$ \\
Eletrocardiograma & 51 & 96,7 \\
Radiografia de tórax & 3 & 85,0 \\
Ecocardiograma & & 5,0 \\
& & \\
Tratamento & 31 & 51,7 \\
Diurético (furosemida) & 27 & 45,0 \\
Inotrópico (dobutamina) & 8 & 13,3 \\
Vasodilatador & 6 & 10,0 \\
Reposição de volume & 3 & 5,0 \\
Ventilação não invasiva & 1 & 1,7 \\
Hemodiálise & 1 & 1,7 \\
Noradrenalina & & \\
Outros & & 13,3 \\
Avaliação pela equipe de marcapasso & 8 & 1,5 \\
Avaliação pela equipe de arritmia & 1 & 1,7 \\
Avaliação pela equipe de transplante & 1 & 1,7 \\
Encaminhamento para cirurgia & 1 & \\
\hline
\end{tabular}

Todos os pacientes foram avaliados pelo médico do prontosocorro por meio de exame físico. Conforme demonstrado na Tabela 18, a realização de ECG e radiografia de tórax foi frequente. Além disso, pacientes com necessidades específicas relativas a arritmia, MPD, transplante e cirurgia foram avaliados por equipes médicas de subespecialidades da cardiologia. Os medicamentos mais utilizados foram furosemida e dobutamina.

$\mathrm{Na}$ Tabela 19 são apresentados os principais desfechos dos pacientes com IC descompensada, internados no pronto-socorro. 
Tabela 19 - Principais desfechos em pacientes com Insuficiência Cardíaca descompensada, internados no prontosocorro. Incor,São Paulo - 2011

\begin{tabular}{lcc}
\hline \multirow{2}{*}{ Desfechos } & \multicolumn{2}{c}{ Grupo B } \\
\hline Transferência para enfermaria & $\mathbf{n}$ & $\%$ \\
Alta hospitalar & 20 & 33,3 \\
Óbito & 18 & 30 \\
Transferência para unidade de terapia intensiva & 11 & 18,3 \\
Transferência para outro serviço & 7 & 11,7 \\
\hline Total & 4 & 6,7 \\
\hline
\end{tabular}

A análise descritiva do tempo de internação mostrou que os pacientes permaneceram 5,9 $( \pm 5,1)$ dias no pronto-socorro, sendo então transferidos para outras unidades onde permaneceram no total, em média $19,6( \pm 17,8)$ dias. Dois pacientes permaneciam internados na data da coleta de dados. Embora 30\% dos pacientes tenham recebido alta hospitalar após serem tratados no pronto-socorro, a letalidade e a internação foram muito frequentes. 
Díscussão 


\section{DISCUSSÃO}

Os dados do perfil sócio-demográfico destacados na discussão são aqueles que se diferenciam ou que reforçam dados de estudos anteriores. Além disso, consideramos os dados com diferenças estatisticamente significativas entre o Grupo A e o Grupo B, que possam estar relacionadas às questões envolvidas no autocuidado e na ocorrência de ICD.

Os dados relacionados à situação conjugal corroboram com estudo que afirma que pacientes casados têm apoio social elevado, o que contribui para o melhor estado emocional e melhor qualidade de vida ${ }^{84}$. Por outro lado, morar sozinho pode estar relacionado ao aumento de taxas de readmissão hospitalar em pacientes com doença crônica ${ }^{85}$. Embora estudo mais recente tenha contrariado estes dados, pois não comprovou existência de relação entre apoio social e situação conjugal, os autores afirmam que o apoio social tem sido um fator que facilita o enfrentamento da doença e sugerem que o enfermeiro inclua a avaliação do apoio social no planejamento da sua assistência ${ }^{86}$.

O baixo nível de escolaridade observado nos Grupos A e B pode estar associado a vários desfechos, incluindo ICD, todas as causas de hospitalização e mortalidade. Autores afirmam que pacientes com IC com baixa escolaridade podem não se beneficiar das orientações e intervenções educativas. Por isso, sugerem intervenções específicas para satisfazer as necessidades destes pacientes ${ }^{87,88}$.

Sobre as diferenças de renda, ocupação e idade entre os grupos, outros estudos destacaram a influência, principalmente da baixa renda no aumento de readmissões hospitalares ${ }^{89,90}$. A média de idade dos pacientes foi inferior à média descrita na literatura internacional, dado também observado em outros estudos brasileiros ${ }^{91,92}$. Embora tenhamos observado mais indivíduos idosos no Grupo B. 
Dessa forma, nosso estudo confirma o perfil sócio-demográfico de outros estudos brasileiros sobre pacientes com IC, caracterizado por pacientes mais jovens e com menor grau de escolaridade, comparado a pacientes de estudos internacionais. No entanto, observamos diferença significativa entre os grupos, partindo da comparação entre as médias de idade e de renda financeira, com pior resultado no Grupo B.

Apesar dos resultados controversos de estudos sobre a importância do apoio social no manejo da IC e de termos observado diferenças pouco expressivas, relacionadas ao apoio social devemos considerar o fato de termos encontrado mais pacientes sem companheiro, residindo com outros parentes ou morando sozinhos no Grupo B. Neste grupo, identificamos mais pacientes aposentados ou afastados do trabalho, o que compromete a renda financeira e também o convívio social. Estes resultados reforçam recomendações de estudos anteriores sobre a necessidade de abordagens educativas específicas para determinados grupos e da importância de considerar o apoio social na abordagem destes pacientes ${ }^{56,59,86}$.

Apesar da etiologia isquêmica ter sido a mais frequente, os números são inferiores quando comparados aos dados internacionais (acima de $50 \%)^{93}$. Esta diferença está provavelmente relacionada à maior frequência das etiologias chagásica e hipertensiva no contexto brasileiro.

Os pacientes com IC de etiologia chagásica apresentaram piores resultados de classe funcional, seguido dos pacientes com etiologia valvar. Além disso, foram mais frequentes no Grupo B do que no Grupo A. Estudo brasileiro recente apresentou resultados semelhantes e identificou um maior percentual de pacientes chagásicos em classe funcional III e IV, além do uso mais frequente de marcapasso artificial e pior qualidade de vida relacionada à saúde (QVRS). As autoras sugerem que em países onde uma grande proporção dos pacientes com IC tem etiologia chagásica, necessitam desenvolver mais pesquisas para uma melhor compreensão 
do problema de saúde causado por esta condição e para desenvolver formas de melhorar QVRS neste grupo específico ${ }^{94}$.

Em nosso estudo, independente da etiologia, os pacientes do grupo B, em sua maioria, estavam entre classe funcional III e IV, demonstrando que constituíam o grupo mais sintomático.

O uso de IECA foi menos frequente no Grupo B, embora seu uso seja indicado a pacientes com disfunção sintomática ou assintomática de ventrículo esquerdo (VE), com classe de recomendação I e nível de evidência $A^{1}$. Este fato pode ter contribuído para a readmissão hospitalar e para o histórico de mais internações no último ano neste grupo.

Fatores como anemia e função renal diminuída são reconhecidos atualmente como preditores de mau prognóstico em longo prazo em pacientes com IC grave ${ }^{95}$. Em estudo brasileiro, no qual os pacientes com IC avançada anêmicos eram mais idosos e com função renal mais deteriorada, os autores concluíram que a anemia é marcador independente de mau prognóstico $^{96}$.

Em nosso estudo, observamos um pior perfil clínico no Grupo B, caracterizado pelo número elevado de chagásicos, pacientes em classe funcional entre III e IV, piores níveis de ureia, creatinina e hemograma. Estes dados condizem com afirmação de que estes aspectos clínicos são preditores independentes de mau prognóstico e que, portanto, podem ter influenciado na descompensação da IC.

Os dados relacionados à ocorrência de internações não planejadas no último ano estão de acordo com resultado de estudo que buscou definir a taxa de readmissão para idosos com IC. Os autores afirmam que a internação por IC aguda por si gera mais hospitalização, com taxas de re-hospitalização de até $50 \%$ dentro dos 12 meses após alta hospitalar $^{97}$. 
Os resultados sobre percepção de piora clínica e procura pela equipe de saúde condiz com questionamento que motivou estudo recente sobre a diferença no autocuidado de pacientes novatos e experientes com sintomas de IC. Os autores, baseados em teoria específica de autocuidado, acreditavam que o nível de experiência poderia ser um determinante na gestão e manutenção do autocuidado, porém no estudo, este aspecto não pareceu prever a confiança do paciente em participar do autocuidado ${ }^{98}$. Em nosso estudo, independente de ter ou não vivenciado sintomas de piora clínica, os pacientes relataram avisar o médico ou enfermeiro sobre os sinais de descompensação, sendo que valorizam mais a falta de ar, seguido de edema e aumento do peso. Apesar de não haver diferença significativa, o Grupo B demonstrou manejar melhor o uso do diurético, principalmente em casos de piora do edema, o que reforçaria o conceito da influência da vivência de piora clínica no autocuidado.

Os resultados sobre vacinação são semelhantes aos resultados de um estudo brasileiro ${ }^{99}$ que constatou que a taxa de vacinação contra influenza e pneumococo em pacientes com IC é muito baixa e ainda menor naqueles descompensados atendidos em serviço de emergência. Os autores desse estudo ressaltam a necessidade de implementação de medidas para incrementar a taxa de vacinação contra infecções respiratórias nos pacientes com IC e, desta forma, diminuir as readmissões hospitalares.

Em nosso estudo, observamos que os pacientes valorizam a falta de ar como sintoma de piora clínica e entendem a importância de comunicar o médico ou enfermeiro, além de adotar medidas como restrição hídrica e manejo do diurético. No entanto, pouco mais da metade dos pacientes em ambos os grupos, entendem a importância do aumento do edema periférico e do aumento de peso. Além disso, embora a maioria dos pacientes tenha relatado facilidade para se pesar diariamente, observou-se que a orientação sobre controle de peso é pouco adotada pelos profissionais. Outro dado importante é que menos da metade dos pacientes de nosso estudo estavam com a vacinação contra a gripe atualizada, sendo que a maioria atribuiu esta 
condição à falta de orientação por parte dos médicos e enfermeiros. Estes dados sugerem a necessidade de intervenções direcionadas a aspectos específicos do autocuidado em pacientes com IC e intervenções direcionadas aos profissionais que realizam as orientações no ambulatório.

O escore total de adesão ao tratamento de nossos pacientes foi menor se comparado ao grupo intervenção do Remadhe ${ }^{64}$, que recebia intervenções educativas prolongadas na época do estudo. No entanto, foi maior que o escore do grupo controle que recebia tratamento usual no ambulatório na época do estudo. Esta diferença pode ter ocorrido, pois os pacientes incluídos em nosso estudo não foram questionados quanto à participação em estudo prévio. Desta forma, considera-se que os pacientes apresentam bom escore de adesão, já que parte deles continuam recebendo as orientações usuais do estudo supracitado no ambulatório, durante as consultas de rotina.

O escore de adesão por item do instrumento demonstrou diferença significativa apenas nas questões relativas à adição de tempero, molhos e outros alimentos industrializados com sal nas refeições e ingestão de bebida alcoólica. A melhor adesão do Grupo B, assim como na percepção de piora clínica, pode ter sido influenciada pela experiência das internações prévias e pelo autocuidado.

O perfil hemodinâmico com predomínio de congestão é a forma mais comum de apresentação da IC descompensada, conforme dados nacionais e internacionais 92,100,101. Nossos dados confirmaram esta observação e também apresentaram com frequência a associação de congestão e baixo débito, além de baixo débito sem sinais de congestão. Diante disso, a necessidade de droga vasoativa, o tempo prolongado de internação e a maior letalidade foram muito frequentes. Podemos atribuir esses achados a possível maior gravidade dos nossos pacientes, atendidos em hospital especializado em cardiologia, o qual é referência para o tratamento de IC avançada, conforme resultados de estudo realizado ${ }^{92}$. 
A gravidade dos pacientes e as características encontradas no grupo $B$ são semelhantes à de outros estudos, os quais observaram que pacientes com quadro de choque cardiogênico, insuficiência renal, doença de Chagas, com grande comprometimento miocárdico e aqueles mal orientados se encontram no grupo com pior evolução ${ }^{102,103}$. Embora não tenhamos encontrado resultados negativos quanto à adesão ao tratamento em nosso estudo.

O tempo de internação para compensação dos pacientes com IC foi muito grande, maior do que o descrito na literatura, em média de nove dias para pacientes graves ${ }^{104,105}$. Os pacientes do Grupo B, admitidos no pronto-socorro, permaneceram 5,9 $( \pm 5,1)$ dias no Pronto-socorro, sendo então transferidos para outras unidades onde permaneceram no total, em média 19,6 $( \pm 17,8)$ dias, sendo que apenas $30 \%$ receberam alta após compensação no pronto-socorro. Este resultado é semelhante ao de um estudo nacional que buscou avaliar a atual história natural da IC por meio da taxa de mortalidade e de re-hospitalizações na mesma população, cujos resultados mostraram que o tempo médio de internação foi de 25,1( $\pm 16,7$ dias $)^{106}$. Sabe-se que 0 tempo de internação para compensação dos pacientes é um aspecto importante, pois implica nos custos do tratamento. Os pacientes mais graves e com mais co-morbidades necessitam de tempo maior para compensação e custarão mais para o sistema de saúde.

O fato de não termos encontrado diferença no escore de adesão ao tratamento e em ações de autocuidado, observarmos diferenças no perfil sociodemográfico e clínico entre os grupos e identificarmos as características de gravidade dos pacientes do Grupo B, sugerem que há outros fatores que predispõem pacientes com IC à descompensação e readmissões hospitalares.

Sobre os fatores precipitantes de descompensação, estudo multicêntrico buscou identificar a associação entre fatores precipitantes identificados no momento da admissão hospitalar por IC descompensada e 
desfechos clínicos posteriores. Os principais fatores identificados foram: infecção respiratória, arritmias, isquemia e baixa adesão à dieta e medicamentos. Este último foi associado à retenção excessiva de sódio e considerado a principal causa de descompensação (55\% dos 975 pacientes). Cerca de dois terços dos pacientes estudados tinham um ou mais fatores precipitantes. Os autores afirmaram que vários destes fatores, incluindo a baixa adesão à dieta e aos medicamentos, podem ser abordados por meio de estratégias de educação em saúde ${ }^{107}$.

Estudo brasileiro recente, que buscou relacionar a adesão com o número de internações hospitalares teve resultados que reforçam este achado. Embora os autores tenham constatado que a baixa adesão ao tratamento estivesse entre as principais causas de descompensação da IC, o número de internações e re-internações no período de um ano não se relacionou à adesão ao tratamento farmacológico e não farmacológico ${ }^{108}$.

Em nosso estudo, fatores relacionados ao perfil sociodemográfico e clínico foram identificados no Grupo B. No entanto, apesar de termos observado dificuldade em algumas ações de autocuidado específicas para IC, elas foram semelhantes no Grupo A e Grupo B. Além disso, nossos pacientes tiveram um bom escore do instrumento que avaliou a adesão ao tratamento. 
Conclusões 


\section{CONCLUSÕES}

Considerando os resultados de estudo prévio ${ }^{64}$, os pacientes de nosso estudo apresentam bom escore de adesão. Concluímos que os pacientes realizam parcialmente as ações de autocuidado, devido à dificuldade na percepção de piora clínica relacionada ao aumento recente do peso e edema periférico, bem como a comunicação desta piora à equipe de saúde; controle de peso e vacinação contra influenza.

Não identificamos diferença significativa entre o autocuidado de pacientes do ambulatório e do pronto-socorro.

Dentre os possíveis fatores precipitantes de descompensação dos pacientes do pronto-socorro, encontramos: mais idosos e aposentados, pessoas com baixa renda; mais pessoas residindo sozinhas ou apenas com filhos e sem companheiro; pacientes com pior perfil clínico, devido ao grande número de chagásicos, maioria de pacientes em classe funcional III e IV, mais pacientes com arritmia e uso de marcapasso definitivo, piores níveis de uréia, creatinina e hemoglobina e menor uso de IECA. A avaliação do perfil hemodinâmico dos pacientes do pronto-socorro demonstrou a predominância de pacientes com congestão pulmonar, seguidos de pacientes com baixo débito cardíaco, com ou sem congestão pulmonar, determinando o uso frequente de diuréticos e drogas inotrópicas, relacionados à prolongada internação e à alta letalidade neste grupo. 
Consíderações Finaís 


\section{CONSIDERAÇÕES FINAIS}

A continuidade deste estudo, com seguimento em seis meses, permitirá identificar os principais desfechos a curto prazo, comparando os pacientes da clínica especializada e do pronto-socorro quanto a óbitos, atendimentos de emergência, internações não planejadas, total de dias de internação e número de dias de cada internação. Dessa forma, estão sendo realizados contatos telefônicos com os sujeitos da pesquisa, feitos pela pesquisadora, com término previsto para o final do primeiro semestre de 2012.

A partir dos resultados obtidos neste estudo, sugerimos que sejam realizadas pesquisas voltadas aos pacientes com IC avançada e para grupos específicos, que sejam mais susceptíveis a experimentar internações não planejadas.

Neste sentido, este estudo abre novas perspectivas de pesquisas para os enfermeiros de modo a ampliar a abordagem e o acompanhamento de pacientes em ambiente familiar para avaliar a real situação de realização dos cuidados, visto que os estudos realizados até o momento se basearam em autorrelato. Além disso, recomendamos mais investigações sobre a influência do apoio social na melhora do autocuidado e da QVRS e novas abordagens educativas com foco no autocuidado, voltadas para o paciente e para os familiares.

Intervenções educativas voltadas a aspectos específicos do autocuidado como percepção de piora clínica e comunicação com equipe de saúde, controle de peso e vacinação, bem como a avaliação da eficácia destas intervenções na melhora do autocuidado poderiam ser úteis, além de programas voltados aos profissionais que realizam estas orientações no ambulatório. Os instrumentos para avaliação de adesão ao tratamento e autocuidado poderiam ser utilizados na prática clínica, com o objetivo de 
direcionar as intervenções conforme as necessidades individuais dos pacientes.

Diante do perfil clínico de gravidade encontrado em nosso estudo, especialmente nos pacientes do pronto-socorro, seria importante 0 desenvolvimento de estudos voltados para pacientes com IC avançada e/ou específicos para etiologia chagásica; incluindo a criação de programas de cuidados paliativos, direcionados a pacientes sem possibilidade de transplante cardíaco, considerando que em grandes centros especializados como o Incor, a mortalidade hospitalar é alta nestes pacientes.

Dentre as limitações deste estudo, podemos incluir o fato de não termos identificado os sujeitos quanto à participação em estudo prévio, que envolveu a educação prolongada por equipe multiprofissional, o que pode ter influenciado no escore de adesão. Além disso, a avaliação das ações de autocuidado, incluindo o escore de adesão foi autorreferida, podendo, da mesma forma, superestimar os resultados.

Não obstante, reconhecemos as limitações de estudos transversais e prospectivos em curto prazo, além do fato de estudos descritivos correlacionais descreverem a relação entre as variáveis, sem estabelecer uma relação causal. 
Referências 
1 Bocchi EA, Marcondes-Braga FG, Ayub-Ferreira SM, Rohde LE, Oliveira WA, Almeida DR, e cols. Sociedade Brasileira de Cardiologia. III Diretriz Brasileira de Insuficiência Cardíaca Crônica. Arq Bras Cardiol. 2009; 93(1Supl1): 1-71.

2 Stromberg A. Educating nurses and patients to manage heart failure. Eur J Cardiovasc Nurs. 2002:33-40.

3 Ghali JK, Kadakia S, Cooper R, Ferlinz J. Precipitating factors leading to descompensation of Heart Failure: Traits among urban blacks. Arch Intern Med. 1988;148:2013-16.

4 Santos ZMSA, Costa CMV, Saraiva KRO. Cliente portador de insuficiência cardíaca: demandas do autocuidado. Rev Enfermagem Esc Anna Nery. 2004; 8(2):243-50.

5 Wu JR, Moser DK, Lennie TA, Peden AR, Chen YC, Heo S. Factors influencing medication adherence in patients with heart failure. Heart and Lung. 2008; 47(1):8-17.

6 Assis CC, Barros ALBL, Ganzarolli MZ. Avaliação das intervenções e dos resultados esperados para o diagnóstico de enfermagem Fadiga, em portadores de insuficiência cardíaca. Acta Paul Enferm. 2007; 20(3): 357-61.

7 Ferreira MCS, Gallani MCBJ. Insuficiência cardíaca: antiga síndrome, novos conceitos e atuação do enfermeiro. Rev Bras enf. 2005; 58(1):70-73.

8 Aliti GB, Rabelo ER, Domingues FB, Clausell N. Cenários de educação para o manejo de pacientes com insuficiência cardíaca. Rev Latino-a Enfermagem. 2007;15(2):344-9.

9 Buck P, Arteaga E, Tirone A. Formas de abordagem do profissional de enfermagem no seguimento de pacientes com cardiomiopatia e insuficiência cardíaca. Rev Socesp. 2003;13(4):541-46.

10 Baker DW, Asch SM, Keesey JW, Brown JA, Chan KS, Joyce G, et al. Differences in Education, Knowledge, self-management, activities and health outcomes for patients with heart failure cared for under the chronic disease model: The Improving Chronic Illness Evaluation. J Card Fail. 2005;11(6):405-413. 
11 Agard A, Hermerén G, Herlitz J. When is a patient with heart failure adequately informed? A study of patients' knowledge of and attitudes toward medical information. Heart and Lung. 2004; 33(4):219-226.

12 Rabelo ER, Aliti GB, Domingues FB, Ruschel KB, Brun AO. O que ensinar aos pacientes com insuficiência cardíaca e por quê: o papel dos enfermeiros em clínicas de insuficiência cardíaca. Rev Latino-am Enfermagem. 2007; 15 (1):165-70.

13 Cruz FD. Effect of a sequential education and monitoring programme on quality-of-life components in heart failure. Eur $\mathrm{J}$ Heart Fail. 2010:12(9):1009-15.

14 Martje HL, Van der Wal MH, Jaarsma T, Moser DK, Veeger NJGM, Gilst WHV, et al. Compliance in heart failure patients: the importance of knowledge and beliefs. Eur Heart Journal. 2006;27:434-440.

15 Lloyd-Jones D, Adams R, Carnethon M, et al. Heart disease and stroke statistics--2009 update: a report from the American Heart Association Statistics Committee and Stroke Statistics Subcommittee. Circulation. 2009 Jan 27;119(3): 21-181.

16 Rossi Neto JM. A dimensão do problema da insuficiência cardíaca no Brasil e no Mundo. Rev Socesp. 2004;14(1):1-10.

17 Najafi $F$ et al. Understanding the 'epidemic of HF': a systematic review of trends in determinants of HF. Eur J Heart Fail. 2009;11(5):472-9.

18 Mendez GF, Cowie MR. The epidemiological features of heart failure in developing countries: a review of the literature. Int $\mathrm{J}$ Cardiol 2001;80:213-9.

19 Fiorelli Al, Coelho HB, Oliveira Junior JL, Oliveira AS. Insuficiência cardíaca e transplante cardíaco. Rev Med (São Paulo). 2008;87(2):10520.

20 Vilas-Boas F, Follath F. Tratamento atual da insuficiência cardíaca descompensada. Arq Bras Cardiol. 2006; 87(3): 369-77.

21 Godoy HL, Silveira JS, Segalla E, Almeida DR. Hospitalização e Mortalidade por Insuficiência Cardíaca em Hospitais Públicos no Município de São Paulo. Arq Bras Cardiol. 2011;97(5):402-7. 
22 Montera MW, Almeida RA, Tinoco EM, Rocha RM, Moura LZ, Réa-Neto A, et al. Sociedade Brasileira de Cardiologia. II Diretriz Brasileira de Insuficiência Cardíaca Aguda. Arq Bras Cardiol. 2009;93(3 supl3):1-65.

23 Ministério da Saúde. Secretaria de Vigilância em Saúde. Brasil. Brazilian Consensus on Chagas disease. Rev Soc Bras Med Trop. 2005;38(supl 3):7-29.

24 Freitas HFG, Castro PPN, Chizzola PR, Bocchi EA. Transplante cardíaco em portadora de endomiocardiofibrose. Arq Bras Cardiol. 2005;84:49-54.

25 Bocchi EA, Guimarães G, Tarasoutshi F, Spina G, Mangini S, Bacal F. Cardiomyopathy, adult valve disease, and heart failure in South América. Heart 2009;95:181-9.

26 Gaui EN, Klein $\mathrm{CH}$, Oliveira GM. Mortality due to heart failure: extended analysis and temporal trend in three states of Brazil. Arq Bras Cardiol. 2010;94(1):55-61.

27 Di Bari M, Pozzi C, Cavallini MC, Innocenti F, Baldereschi G, De Alfieri $\mathrm{W}$, et al. The diagnosis of heart failure in the community. Comparative validation of four sets of criteria in unselected older adults: the ICARe`Dicomano Study. J Am Coll Cardiol. 2004;44:1601-8.

28 Rabelo E, Aliti GB, Goldraich L, Domingues FB, Clausell N, Rohde LE. Manejo não farmacológico de pacientes hospitalizados com insuficiência cardíaca em hospital universitário. Arq Bras Cardiol. 2006; 87(3):352-8.

29 Wu JR, Moser DK, Lennie TA, Burkhart PV. Medication adherence in patients who have heart failure: a review of the literature. Nurs Clin North Am. 2008; 43(1):133-53.

30 Bocchi EA, Marcondes-Braga FG, Bacal F, Ferraz AS, Albuquerque D, Rodrigues D, et al. Sociedade Brasileira de Cardiologia. Atualização da Diretriz Brasileira de Insuficiência Cardíaca Crônica - 2012. Arq Bras Cardiol. 2012:98(1 supl 1):1-33.

31 Filippatos G, Zannad F. An introduction to acute heart failure syndromes: definition and classification. Heart Fail Rev. 2007;12(2):8790 . 
32 Solomon SD, Dobson J, Pocock S, Skali H, McMurray JJ, Granger CB, et al. Candesartan in heart failure: assessment of reduction in mortality and morbidity (CHARM) investigators. Influence of nonfatal hospitalization for heart failure on subsequent mortality in patients with chronic heart failure. Circulation. 2007;116 (13):1482-7.

33 Krumholz $\mathrm{MH}$, Em $\mathrm{P}$, Tu N, et al. The treatment target in acute decompensated heart failure. Rev Cardiovasc Med. 2001;2 Suppl 2:5712.

34 Fonseca C, Oliveira AG, Mota T, Matias F, Morais H, Costa C, et al. Evaluation of the performance and concordance of clinical questionnaires for the diagnosis of heart failure in primary care. Eur $\mathrm{J}$ Heart Fail. 2004; 6(6): 813-2.

35 Nohria A, Tsang SW, Fang JC, Lewis EF, Jarcho JA, Mudge GH, et al. Clinical assessment identifies hemodynamic profiles that predict outcomes in patients admitted with heart failure. J Am Coll Cardiol. 2003;41(10):1797-804.

36 Shah MR, Hasselblad V, Stinnett SS, Gheorghiade M, Swedberg K, Califf RM, et al. Hemodynamic profiles of advanced heart failure: Association with clinical characteristics and long-term outcomes. J Card Fail. 2001;7(2):105-13.

37 Cleland JG, Swedberg K, Follath F, Komajda M, Cohen-Solal A, Aguilar $\mathrm{JC}$, et al. The Euro Heart failure survey programme: a survey on the quality of care among patients with heart failure in Europe.Part 1: patient characteristics and diagnosis. Eur Heart J. 2003; 24(5):442-63.

38 Thomas SS, Nohria A. Hemodynamic Classifications of Acute Heart Failure and Their Clinical Application. Circ J. 2012;76:278- 86.

39 Jessup M, Abraham WT, Casey DE, Feldman AM, Francis GS, Ganiats TG, et al. 2009 focused update: ACCF/AHA Guidelines for the Diagnosis and Management of Heart Failure in Adults: a report of the American College of Cardiology Foundation/American Heart Association Task Force on Practice Guidelines: developed in collaboration with the International Society for Heart and Lung Transplantation. Circulation. 2009;119(14):1977-2016.

40 Barretto ACP, Del Carlo CH, Cardoso JN, Morgado PC, Munhoz RT, Oliveira Jr. MT, et al. Re-hospitalizações e morte por insuficiência 
cardíaca: índices ainda alarmantes. Arq Bras Cardiol. 2008; 91(5):33541.

41 Püschel VAA, Pinheiro CF, Peruchi F. Cuidar Do Adulto E Do Idoso Com Doença Cardiovascular: Abordagem Psicossocial. Rev Pau Enf. 2006; 25:189-95.

42 Horwitz RI, Horwitz SM. Adherence to treatment and health outcomes. Arch Intern Med. 1993;153(16):1863-8.

43 Haynes RB. Determinants of compliance: The disease and the mechanics of treatment. Baltimore MD: Johns Hopkins University Press, 1979.

44 Rand CS. Measuring adherence with therapy for chronic diseases: implications for the treatment of heterozygous familial hypercholesterolemia. Am J Cardiol. 1993;72:68D-74D.

45 Zanini AC, Paulo LG. Expectativas, dúvidas e fantasias da consulta médica. In: Zanini AC, Paulo LG. Compliance: sobre o encontro paciente-médico.São Paulo: Ipex, 1997, cap.1, p.1-8.

46 Gusmão JL, Mion Jr D. Adesão ao tratamento: conceitos. Rev Bras Hipertens . 2006;13(1): 23-25 .

47 Orem DE. Nursing: concepts of practice, 5ed. St Louis: Mosby, 1995.

48 Foster PC, Benett AM. Dorothea E. Orem. In:George JB. Teorias de enfermagem: Dos fundamentos a pratica profissional [tradução de Ana Maria Vasconcellos Thorell]. 4a ed. Porto Alegre: Artmed; 2000.375 p. p. 83-101.

49 Jaarsma T, Stromberg A, Martensson J, Dracup K. Development and testing of the European Heart Failure Self-Care Behavior Scale. Eur J Heart Fail. 2003;5:363-70.

50 Riegel B, Carlson B, Moser DK, Sebern M, Hicks FD, Roland V. Psychometric testing of the self care of heart failure index. J Card Fail.2004;10:350-60.

51 Riegel B, et al. State of the science: Promoting self care in persons with heart failure: A scientific statement from the Americam Heart Association. J Card Fail. 2009:120;1141-163. 
52 Riegel B, Carlson B, Glaser D. Development and testing of a clinical tool measuring self-management of heart failure. Heart Lung. 2000;29:4-12.

53 Nascimento, HR. Insuficiência Cardíaca: O que os enfermeiros brasileiros estão estudando? Rev. Socesp supl. 2009;19: 3-7.

54 Jaarsma T, Halfens R, Huijer Abu-Saad H, Dracup K, Gorgels T, Van Ree $\mathrm{J}$, et al. Effects of education and support on self care resource utilization in patients with heart failure. Eur Heart J. 1999;20(9):673-82.

55 Ni H, Nauman D, Burgess D, Wise K, Crispell K, Hershberger RE. Factors influencing knowledge of and adherence to self care among patients with heart failure. Arch Intern Med. 1999;159(14):1613-9.

56 Luniewski M, Reigle J, White B. Card sort: an assessment tool for the education needs of patients with heart failure. Am J Crit Care. 1999;8(5):297-302.

57 Buetow SA, Coster GD. Do general practice patients with heart failure understand its nature and seriousness and improved information? Patient educ couns. 2001;45:181-185.

58 Sridhar FG, Guyatt GH, Arnold JMO, Massel D, Brown J, Nadeau L, et al. Instruments to measure acceptability of information and acquisition of knowledge in patients with heart failure. Eur J heart fail. 2003; 5: 783791.

59 DeWalt DA, Pignone M, Malone R, Rawls C, Kosnar MC, George G, et al. Development and pilot testing of a disease management program for low literacy patients with heart failure. Patient educ couns. 2004;55:7886.

60 Saccomann ICRS. Qualidade de vida em idosos portadores de insuficiência cardíaca: avaliação de um instrumento específico [dissertação de mestrado]. Campinas: Universidade Estadual de Campinas. Faculdade de Ciências Médicas, 2006.

61 Tiesinga LJ, Dassen TW, Halfens RJ. DUFS and DEFS: Development, reliability and validity of the Dutch Fatigue Scale and the Extertion Fatigue Scale. Int J Nurs Stud. 1998;35(1-2):115-23. 
62 Bennett SJ, Perkins SM, Lane KA, Forthofer MA, Brater DC, Murray MD. Reliability and validity of the compliance belief scales among patients with heart failure. Heart and Lung 2001;30:177-85.

63 Ávila CW, Feijó MKEF, Souza EN, Rabelo ER. Tradução, adaptação e validação da versão brasileira da European Heart Failure Self-Care Behavior Scale. Resumo das Comunicações 65ํㅡㄹ Congresso Brasileiro de Cardiologia. Arq Bras Cardiol. 2010; 95 (3 supl. 1): 1-192.p.152.

64 Bocchi EA, et al. Long-Term Prospective, Randomized, Controlled Study Using Repetitive Education at Six-Month Intervals and Monitoring for Adherence in Heart Failure Outpatients. The REMADHE Trial. Circ Heart Fail. 2009;1:115-24.

65 Feldman PH, Murtaugh CM, Pezzin LE, McDonald MV, Peng TR. Justin-time evidence-based e-mail reminders in home health care: impact on patient outcomes. Health Serv Res. 2005; 40(3):865-85.

66 Inglis SC, Pearson S, Treen S, Gallasch T, Horowitz JD, Stewart S. Extending the horizon in chronic heart failure: effects of multidisciplinary, home-based intervention relative to usual care. Circulation. 2006; 114(23):2466-73.

67 De la Porte PW, Lok DJ, Van Veldhuisen DJ, Van Wijngaarden J, Cornel JH, Zuithoff NP, et al. Added value of a physician-and-nursedirected heart failure clinic: results from the Deventer-Alkmaar heart failure study. Heart. 2007; 93:819-25.

68 Jaarsma T, et al. Effect Of Moderate Or Intensive Disease Management Program On Outcome In Patients With Heart Failure: Coordinating Study Evaluating Outcomes Of Advising And Counseling In Heart Failure (Coach). Arch Intern Med. 2008;168(3):316-24.

69 Brandon AF, Schuessler JB, Ellison KJ, Lazenby RB. The effects of an advanced practice nurse led telephone intervention on outcomes of patients with heart failure. Applied Nursing Research.2009; 22(4): 1-7.

70 Aguado O, Morcillo C, Delàs J, Rennie M, Bechich S, Schembari, et al. A Long-term implications of a single home-based educational intervention in patients with heart failure. Heart \& Lung. 2010; (6 Supl):14-22. 
71 Smeulders ES, Van Haastregt JC, Ambergen T, Uszko-Lencer NH, Janssen-Boyne JJ, Gorgels AP, et al. Nurse-led self-management group programme for patients with congestive heart failure: randomized controlled trial. J Adv Nurs. 2010; 66(7):1487-99.

72 Powell LH, et al. Self-management Counseling in Patients With Heart Failure. The Heart Failure Adherence and Retention Randomized Behavioral Trial. Jama 2010;304(12):1331-38.

73 Freitas MT. Conhecimento e Significado da doença: expressões de pessoas com insuficiência cardíaca [dissertação] São Paulo: Escola de Enfermagem, Universidade de São Paulo; 2010.

74 Domingues FB, Clausell N, Aliti GB, Dominguez DR, Rabelo ER. Educação e Monitorização por Telefone de Pacientes com Insuficiência Cardíaca: Ensaio Clínico Randomizado. Arq Bras Cardiol. 2011;96(3):233-239.

75 Paradis V, Cossette S, Frasure-Smith N, Heppell S, Guertin M. The efficacy of a motivational nursing intervention based on the stages of change on self-care in heart failure patients. J Cardiovasc Nurs. 2012; 25(2):130-41.

76 Polit DF, Beck CT, Hungler BP. Fundamentos de pesquisa em enfermagem: métodos, avaliação e utilização. 5 ed. Porto Alegre: Artmed; 2004;p.163-77.

77 Serapioni M. Métodos qualitativos e quantitativos na pesquisa social em saúde: Algumas estratégias para a integração. Ciênc Saúde Coletiva. 2000;5(1):187-92.

78 Unidade de informações médicas e hospitalares do instituto coração do hospital das clínicas da fmusp. Disponível em: $<$ http://www.incor.usp.br>. Acesso em 27 mar 2010.

79 Unidade de informações médicas e hospitalares do instituto coração do hospital das clínicas da fmusp. Disponível em: $<$ http://www.incor.usp.br>. Acesso 27 mar 2010.

80 Agresti A. Categorical data analysis. 2ed. Flórida: wiley interscience;2002. 
81 Morettin PA, Bussab WO. Estatística Básica. 6a ed. São Paulo: Saraiva; 2010.

82 Siegel S, Castellan NJ. Nonparametric Statistics. 2ed. New York: McGraw-Hill;1988.

83 Allen MJ, Yen W M. Introduction to Measurement Theory. Long Grove, IL: Waveland Press; 2002.

84 Bennett SJ, Perkins SM, Lane KA, Deer M, Brater DC, Murray MD. Social support and health-related quality of life in chronic heart failure patients. Qual Life Res. 2001;10:671-82.

85 Berkman B, Millar S, Holmes W, Bonander E. Predicting cardiac patients at risk for readmission. Soc Work Health Care. 1991;16(1):2138.

86 Dantas RAS, Pelegrino VM, Garbin ML. Avaliação do Apoio Social e sua relação com variáveis sociodemográficas de pacientes com Insuficiência Cardíaca em Seguimento Ambulatorial. Cienc Cuid Saúde. 2007; 6(4):456-62

87 DeWalt DA, Broucksou KA, Hawk V, Baker DW, Schillinger D, Ruo B, et al. Comparison of a one-time educational intervention to a teach-to-goal educational intervention for self-management of heart failure: design of a randomized controlled trial. BMC Health Serv Res. 2009; 9(99).

88 Smeulders ES, van Haastregt JC, Ambergen T, Stoffers HE, JanssenBoyne JJ, Uszko-Lencer $\mathrm{NH}$, et al. Heart failure patients with a lower educational level and better cognitive status benefit most from a selfmanagement group programme. Patient Educ Couns. 2010;81(2):21421.

89 Rathore SS, Masoudi FA, Wang Y, Curtis JP, Foody JM, Havranek EP, et al. Socioeconomic status, treatment and results with heart failure: findings from the national Heart Failure Project. Am Heart $\mathrm{J}$. 2006;152(2):371-8.

90 Phibin EF, William Dec G, Jenkins PL, DiSalvo TG. Socioeconomic status as an independent risk factor for hospital readmission for heart failure. Am J Cardiol. 2001;87(12):1367-71. 
91 Margoto G, Colombo RC, Gallani MC. Características clínicas e psicossociais do paciente com insuficiência cardíaca que interna por descompensação clínica. Rev Esc Enferm USP. 2009;43(1):44-53.

92 Mangini S, Silveira FS, Silva CP, Grativvol PS, Seguro LF, Ferreira SM, et al. Insuficiência Cardíaca Descompensada na Unidade de Emergência de Hospital Especializado em Cardiologia. Arq Bras Cardiol. 2008;90:400-6.

93 Adams KF Jr, Fonarow GC, Emerman $\mathrm{CH}$, Le Jemtel TH, Costango MR, Abraham WT, et al. Characteristics and outcomes of patients hospitalized for heart failure in the United States: rationale, design and preliminary observations from the first 100000 cases in the Acute Decompensated Heart Failure National Registry (ADHERE). Am Heart J. 2005;149: 209-16.

94 Pelegrino VM, Dantas RA, Ciol MA, Clark AM, Rossi LA, Simões MV. Health-related quality of life in Brazilian outpatients with Chagas and non-Chagas cardiomyopathy. Heart Lung. 2011;40(3):e25-31.

95 Al-Ahmad A, Rand WM, Manjunath G, et al. Reduced kidney function and anemia as risk factors for mortality in patients with left ventricular dysfunction. J Am Coll Cardiol. 2001;38:955-62.

96 Cardoso J, Brito MI, Ochiai ME, Novaes M, Berganin F, Thicon T, et al. Anemia nos Pacientes com Insuficiência Cardíaca Avançada. Arq Bras Cardiol. 2010; 95(4):524-29.

97 Krumholz HM, Parent EM, Vaccarino V, Wang Y, Radford MJ, et al. Readmission after hospitalization for congestive heart failure among medicare beneficiaries. Arch intern med. 1997;157(1):99-104.

98 Cameron J, Worrall-Carter L, Page K, Stewart S. Self-care behaviors and heart failure: Does experience with symptoms really make a difference? Eur Cardiovascular Nurs. 2010; 9:92-100.

99 Martins WA, Ribeiro MD, Oliveira LB, Barros LSN, Jorge ACSM, Santos $\mathrm{CM}$, et al. Vacinação Contra Influenza e Pneumococo na Insuficiência Cardíaca - uma Recomendação Pouco Aplicada. Arq Bras Cardiol. 2011; 96(3):240-45. 
100 Nieminem MS, Brutsaert D, Dickstein K, Drexler H, Follath F, Haryola VP, et al. EuroHeart Failure Survey II (EFHS II): a survey on hospitalized acute heart failure patients: description of population. Eur Heart J. 2006; 27: 2725-36.

101 Montera MW, Viegas M, Bandeira A, Bandeira A, Scofano M, Marques I, et al. Clinical profile and prognostic risk assessment of patients with acute heart failure with preserved systolic function versus systolic dysfunction. Rev SOCERJ. 2006;19: 208-14.

102 Pocock SJ, Wang D, Pfeffer MA, Yusuf, S, McMurray JJ, Swedberg KB, et al. Predictors of mortality and morbidity in patients with chronic heart failure. Eur Heart J. 2006;27: 65-75.

103 Freitas HGF, Chizzola PR, Paes AT, Lima ACP, Mansur AJ. Risk stratification in a Brazilian hospital-based cohort of 1220 outpatients with heart failure: role of Chagas' disease. Int J Cardiol. 2005;102: 23947.

104 Fonarow GC, Adams KJ, Abraham WT, Yancy CW, Boscardin WJ for the ADHERE Scientific advisory committee, study group and investigators. Risk stratification for in-hospital mortality in acutely decompensated heart failure: classification and regression tree analysis. JAMA. 2005; 293: 572-80.

105 Rohde LE, Clausell N, Ribeiro JP, Goldraich L, Netto R, Dec GW, et al. Heath outcomes in decompensated congestive heart failure: a comparison of tertiary hospitals in Brazil and United States. Int J Cardiol. 2005; 102: 71-7.

106 Barretto ACP, Del Carlo CH, Cardoso JN, Morgado PC, Munhoz RT, Eid MO, et al. Re-hospitalizações e morte por insuficiência cardíaca: índices ainda alarmantes. Arq Bras Cardiol. 2008;91(5):335-41.

107 Fonarow GC, Abraham WT, Albert NM, et al. Factors identified as precipitating hospital admissions for heart failure and clinical outcomes:findings from OPTIMIZE-HF. Arch Intern Med. 2008;168(8):847-54 .

108 Castro RA, Aliti GB, Linhares JC, Rabelo ER. Adesão ao tratamento de pacientes com insuficiência cardíaca em um hospital universitário. Rev Gaúcha Enferm. 2010;31(2):225-31. 
Apêndices e Anexos 


\section{APÊNDICE 1- INSTRUMENTO 1 ROTEIRO DE ENTREVISTA}

Data da entrevista: 1

Registro Hospitalar:

\section{Perfil sócio-demográfico}

Data: de Nascimento:

1. Sexo: (1)Masculino (2)Feminino

2. Você tem esposo(a) ou namorado(a)? (1) sim (2) não

3. Com quem você mora? (1)esposa(o)/namorada(o) (2)filhos

(3) esposa(o)/namorada e filhos (4)sozinho(a) (5)instituição (6) outros, qual?

4. Quanto à religião, você se considera: (1) Católico(a) (2) Evangélico(a) (3) Espírita (4) Outra, qual?__ (5) Sem religião

5. Caso tenha religião, você é praticante? (1) $\operatorname{sim}(2)$ não

6. Até que série completa estudou? ( ) É analfabeto

7. Profissão:

8. Trabalho: (1) Trabalha (2)Desempregado (3)Aposentado (4) Licença INSS

9. Renda mensal familiar reais.

10. Quantas pessoas dependem dessa renda?

II. Conhecimento da doenç, internacões e acões diante da piora clínica da Insuficiência Cardíaca

11. Há quanto tempo você sabe que tem esta doença do coração? meses

12. Você ficou internado ou foi ao pronto socorro nos últimos doze meses por causa da insuficiência cardíaca?

(1) $\operatorname{sim}$

(2) não

13. Se a resposta for sim: Quantas vezes?

14. Para você é fácil se pesar regularmente?

(1) $\operatorname{sim}$

(2)não 
15. Se não, Por quê?

16. Onde você costuma se pesar? (1)em casa (2)na farmácia (3)no posto de saúde (4)outros Qual?

17. Se você ganha $2 \mathrm{~kg}$ em uma semana, você procura o médico ou enfermeiro? (1) sim (2) não, o que faz?

18. Se sua falta de ar aumenta, você procura o médico ou enfermeiro? (1) sim (2) não, o que faz?

19. Se seus pés e pernas ficam mais inchados, você procura o médico ou enfermeiro?
(1) $\operatorname{sim}$
(2) não, o que faz?

20. Você tomou a vacina da gripe no último ano? (1) sim (2) não

21. Caso a resposta seja não, por quê?

III. Perfil clínico (dados coletados do prontuário)

1 Etiologia: (1) Chagásica (2) Hipertensiva (3) Miocardite (4) Isquêmica (5) Alcoólica (6) Idiopática (7) Valvulopatia (8) Peri-parto

2 Doenças associadas: (1)Doença isquêmica do coração (2)Arritmia cardíaca

(3)Doença Cérebro Vascular (4)Doença Vascular Periférica (5)Diabetes (6)Hipertensão Arterial (7)Obesidade (8)Anemia (9) Doença cardíaca valvar (10)DLP (11)IRC (12) Desnutrição (13)Neoplasia (14)DPOC outras

3 Medicamento em uso: (1)Diurético (2)Digitálico (3)Vasodilatador

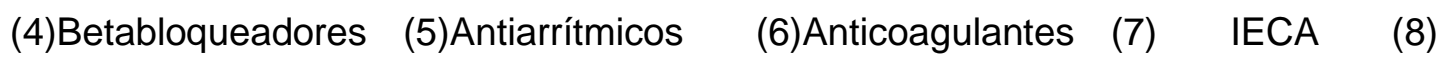
Espironolactona 
4 Classe funcional (NYHA): (1) I (2) II (3) III (4) IV

\begin{tabular}{|l|l|}
\hline Classe funcional & Limitação do paciente nas atividades cotidianas \\
\hline Classe I ( ) & $\begin{array}{l}\text { Nenhuma: sem fadiga, palpitações ou dispneia indevida nas } \\
\text { atividades cotidianas. }\end{array}$ \\
\hline Classe II ( ) & $\begin{array}{l}\text { Pequena, conforto em repouso, com fadiga, palpitações ou } \\
\text { dispneia nas atividades cotidianas. }\end{array}$ \\
\hline Classe III ( ) & $\begin{array}{l}\text { Marcante: conforto em repouso, sintomas em atividades mais leves } \\
\text { que as habituais. }\end{array}$ \\
\hline Classe IV ( ) & $\begin{array}{l}\text { Grave: sintomas em repouso, não consegue realizar nenhuma } \\
\text { atividade física sem desconforto. }\end{array}$ \\
\hline
\end{tabular}

Adaptado de Olmos RD, Martins HS. Insuficiência Cardíaca. In: Martins HS, Neto RAB, Neto AS, Velasco IT. Emergências Clínicas: Abordagem Prática.4룰. Barueri (SP): Manole; 2009.p.283-308.

\section{Ecocardiograma}

(1)Fração de ejeção: (2)Diâmetro sistólico final cm (3) Diâmetro diastólico final $\mathrm{cm}$

\section{Exames laboratoriais:}

$(1) \mathrm{Na} \_\mathrm{mEq} / \mathrm{L} \quad(2) \mathrm{k} \_\mathrm{mEq} / \mathrm{L}(3), \mathrm{Hb} \_\mathrm{g} / \mathrm{L}(4)$ Creatinina _ $\mathrm{mg} / \mathrm{dL}$ (5)Ureia _ (6)BNP _ pg/mL

8 Dispositivos implantados: (1) Stent em coronária (2) Endoprótese aórtica (3)Valva aórtica

(4)Valva mitral (5)Marcapasso (6)Cardiodesfibrilador (7) outros, qual?

\section{Contato telefônico}

Data

Residencial Celular

Que dia pode atender? Seg ( ) Ter ( ) Qua ( ) Qui ( ) Sex ( ) Sáb ( ) Dom ( ) Que horário pode atender? De $h$ às $\mathrm{h}$

1. Você foi ao pronto socorro nos últimos 6 meses por causa da insuficiencia cardíaca?
(1) $\operatorname{sim}$
(2) não

Se a resposta for sim: Quantas vezes? 
2. Você ficou internado nos últimos 6 meses por causa da insuficiencia cardíaca?

(1) $\operatorname{sim}(2)$ não

3. Se a resposta for sim: Quantas vezes?
(1) $(2)$
(2) (3)
(4)
(5) (6)

4. Se a resposta for sim: Quantos dias em cada internação?
(1)
dias
(3)
dias
(5)
dias
(2) _ dias
(4)
dias
(6) dias TOTAL

5. Óbito (1)Sim (2) não 


\section{APÊNDICE 2 - INSTRUMENTO 3}

\section{Perfil Hemodinâmico}

Identificação:

Reg hosp:

Entrada no P.S:

Etiologia:

Dias no P.S

Total de dias de internação
1. Desfechos: (1) alta
(2) transf UTI
(3) Transf Enf
(4) Transf outro serviço (5) Óbito

2. Avaliação clínico-hemodinâmica:

(1) Perfil A: Pacientes sem sinais de congestão ou de baixo débito: quente/seco.

(2) Perfil B: Pacientes congestos sem baixo débito: quente/úmido;

(3) Perfil C: Pacientes congestos com baixo débito: frio/úmido;

(4) Perfil L: Pacientes sem sinais de congestão com baixo débito: frio/seco;

3. Avaliação e monitorização não invasiva:

(1) RX (2) Eletrocardiograma (3) Ecocardiograma (4) Outro

4. Tratamento:
(1) Diurético de alça
( 2 ) Analgésico
(3) Vasodilatador
( 4 ) VNI
(5) Reposição volêmica
(6) Inotrópico Qual?
( 7 ) Outros
Qual? 


\section{ANEXO 1}

\section{TERMO DE CONSENTIMENTO LIVRE E ESCLARECIDO}

DADOS DE IDENTIFICAÇÃO DO SUJEITO DA PESQUISA OU RESPONSÁVEL LEGAL

1. NOME:

DOCUMENTO DE IDENTIDADE No SEXO :.$M \square F \square$ DATA NASCIMENTO: № APTO:

ENDEREÇO: CIDADE:

BAIRRO:

CEP: TELEFONE: DDD ( )

2.RESPONSÁVEL LEGAL:

NATUREZA (grau de parentesco, tutor, curador etc.):

DOCUMENTO DE IDENTIDADE N SEXO :.$M \square F \square$ DATA NASCIMENTO:

ENDEREÇO: № APTO:

BAIRRO: CIDADE:

CEP: TELEFONE: DDD ( )

\section{DADOS SOBRE A PESQUISA}

1. TÍTULO DO PROTOCOLO DE PESQUISA: Autocuidado em Insuficiência Cardíaca: Estudo comparativo entre pacientes de clínica especializada e Pronto Socorro. PESQUISADOR : Edimar Alcides Bocchi

CARGO/FUNÇÃO: Médico / Diretor INSCRIÇÃO CONSELHO REGIONAL № : CRM- 36179 UNIDADE DO HCFMUSP: Instituto do Coração

3. AVALIAÇÃO DO RISCO DA PESQUISA: RISCO MÍNIMO $\square X$ RISCO MÉDIO 口 RISCO BAIXO $\square$ RISCO MAIOR $\square$

4.DURAÇÃO DA PESQUISA : 12 meses 


\section{HOSPITAL DAS CLÍNICAS DA FACULDADE DE MEDICINA DA UNIVERSIDADE DE SÃO PAULO-HCFMUSP}

Convido o (a) senhor (a) a participar voluntariamente da pesquisa "Autocuidado em Insuficiência Cardíaca: Estudo comparativo entre pacientes de clínica especializada e Pronto Socorro, que dará origem a dissertação de mestrado da pesquisadora executante Enfermeira Heloisa Ribeiro do Nascimento. O objetivo deste estudo é identificar como as pessoas com insuficiência cardíaca se cuidam. O conhecimento sobre este cuidado é importante para melhorar as ações em saúde.

A sua participação na pesquisa será respondendo a uma entrevista com dois questionários. O $1^{\circ}$ tem três partes, com 21 perguntas simples e fáceis de responder e algumas informações do seu prontuário. $\mathrm{O} 2^{\circ}$ tem 10 perguntas sobre os seus cuidados específicos para a insuficiência cardíaca. O tempo total previsto para esta entrevista será de 60 minutos. Será necessário um telefonema depois de 6 meses para completar o estudo. Nesta ocasião, o tempo de entrevista será de aproximadamente 15 minutos. Esclareço ao Sr (a) que este estudo foi aprovado pelo Comitê de Ética do Hospital. A duração do estudo será de um ano, dentro deste período terei acesso ao seu prontuário médico.

Os resultados deste estudo ajudarão no planejamento de melhorias no acompanhamento ambulatorial dos pacientes com insuficiencia cardíaca, para prevenir sinais e sintomas da doença e para modificar os fatores que levam à descompensação do coração.

O senhor terá acesso a qualquer tempo às informações relacionadas ao estudo; terá a liberdade de desistir de participar do estudo, sem que isto prejudique o seu atendimento; salvaguarda da confidencialidade, sigilo e privacidade; O estudo não provocará danos a sua saúde. Não terá despesas para o participante em qualquer fase do estudo. Também não terá qualquer pagamento pela sua participação. O pesquisador terá o compromisso de utilizar os dados e o material coletado somente para esta pesquisa.

Em qualquer etapa do estudo, você terá acesso aos profissionais responsáveis pela pesquisa para esclarecimento de eventuais dúvidas. O investigador responsável é o médico Dr. Edimar Alcides Bocchi, que pode ser encontrado no endereço Av. Dr Enéas de Carvalho Aguiar, 44. Telefone(s) 3069 - 5419, e-mail: dcledimar@incor.usp.br. Se você tiver alguma consideração ou dúvida sobre a ética da pesquisa, entre em contato com o Comitê de Ética em Pesquisa (CEP) - Rua Ovídio Pires de Campos, 225 - 5aandar - tel: 3069-6442 ramais 16, 17, 18 ou 20, FAX: 3069-6442 ramal 26 - E-mail: cappesq@hcnet.usp.br.

Acredito ter sido bem informado a respeito das informações que li ou que foram lidas para mim, explicando o estudo "Autocuidado em Insuficiência Cardíaca: Estudo comparativo entre pacientes de clínica especializada e Pronto Socorro". 


\section{HOSPITAL DAS CLÍNICAS DA FACULDADE DE MEDICINA DA} UNIVERSIDADE DE SÃO PAULO-HCFMUSP

Assinatura do paciente/representante legal

Data

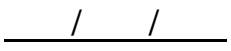

Assinatura da testemunha

Data 11

Eu discuti com o pesquisador responsável Dr Edimar Alcides Bocchi sobre a minha decisão em participar nesse estudo. Ficaram claros para mim quais são os propósitos do estudo, os procedimentos a serem realizados, seus desconfortos e riscos, as garantias de confidencialidade e de esclarecimentos permanentes. Ficou claro também que minha participação é isenta de despesas e que tenho garantia do acesso a tratamento hospitalar quando necessário. Concordo voluntariamente em participar deste estudo e poderei retirar 0 meu consentimento a qualquer momento, antes ou durante o mesmo, sem penalidades ou prejuízo ou perda de qualquer benefício que eu possa ter adquirido, ou no meu atendimento neste Serviço.

Para casos de pacientes analfabetos, semi-analfabetos ou portadores de deficiência auditiva ou visual.

\section{(Somente para o responsável do projeto)}

Declaro que obtive de forma apropriada e voluntária o Consentimento Livre e Esclarecido deste paciente ou representante legal para a participação neste estudo.

Assinatura do responsável pelo estudo

Dr. Edimar Alcides Bocchi

Data 11 


\section{ANEXO 2 - INSTRUMENTO 2}

\section{Questionário de Aderência em Pacientes com Insuficiência Cardíaca}

\section{Medicamentos}

1.1. Toma regularmente os medicamentos de acordo com a prescrição?

0 - nunca $(0 \%)$

1 - quase nunca (de 1 a 2 dias ou de 1 a 13\%)

2 - poucas vezes (durante 3 a 4 dias ou de 20 a 27\%)

3 - algumas vezes (de 5 a 7 dias ou de 33 a 47\%)

4 - a maioria das vezes (de 8 a 11 dias ou de 80 a 93\%)

5 - quase sempre (de 12 a 14 dias ou de 76 a $99 \%$ )

6 - sempre (durante 15 dias ou 100\%)

\section{Alimentação e líquidos}

2.1. Tem se pesado diariamente?

0 - nunca $(0 \%)$

1 - quase nunca (de 1 a 2 dias ou de 1 a 13\%)

2 - poucas vezes (durante 3 a 4 dias ou de 20 a 27\%)

3 - algumas vezes (de 5 a 7 dias ou de 33 a 47\%)

4 - a maioria das vezes (de 8 a 11 dias ou de 80 a 93\%)

5- quase sempre (de 12 a 14 dias ou de 76 a 99\%)

6 - sempre (durante 15 dias ou 100\%)

2.2. Você restringe a adição de sal nos alimentos?

0 - nunca $(0 \%)$

1 - quase nunca (de 1 a 2 dias ou de 1 a 13\%)

2 - poucas vezes (durante 3 a 4 dias ou de 20 a 27\%)

3 - algumas vezes (de 5 a 7 dias ou de 33 a 47\%)

4 - a maioria das vezes (de 8 a 11 dias ou de 80 a 93\%)

5- quase sempre (de 12 a 14 dias ou de 76 a 99\%)

6 - sempre (durante 15 dias ou 100\%)

2.3. Você adiciona temperos, molhos, e outros alimentos industrializados com sal em suas refeições?

0 - sempre (durante 15 dias ou 100\%)

1 - quase sempre (de 12 a 14 dias ou de 76 a $99 \%$ )

2 - a maioria das vezes (de 8 a 11 dias ou de 80 a 93\%)

3 - algumas vezes (de 5 a 7 dias ou de 33 a 47\%)

4 - poucas vezes (durante 3 a 4 dias ou de 20 a 27\%)

5- quase nunca (de 1 a 2 dias ou de 1 a 13\%)

6 - nunca $(0 \%)$

2.4. Você tem se alimentado fora de casa sem restringir o sal?

0 - sempre (durante 15 dias ou 100\%)

1 - quase sempre (de 12 a 14 dias ou de 76 a $99 \%$ )

2 - a maioria das vezes (de 8 a 11 dias ou de 80 a 93\%)

3 - algumas vezes (de 5 a 7 dias ou de 33 a 47\%)

4 - poucas vezes (durante 3 a 4 dias ou de 20 a 27\%)

5- quase nunca (de 1 a 2 dias ou de 1 a 13\%)

6 - nunca $(0 \%)$ 
2.5. Você tem consumido em suas refeições sopas, gelatinas, sorvetes, sucos, leites, chás, cafés, refrigerantes, etc. sem considerar a quantidade de líquido? 0 - sempre (durante 15 dias ou 100\%)

1 - quase sempre (de 12 a 14 dias ou de 76 a 99\%)

2 - a maioria das vezes (de 8 a 11 dias ou de 80 a 93\%)

3 - algumas vezes (de 5 a 7 dias ou de 33 a 47\%)

4 - poucas vezes (durante 3 a 4 dias ou de 20 a 27\%)

5 - quase nunca (de 1 a 2 dias ou de 1 a $13 \%$ )

6 - nunca $(0 \%)$

2.6. Você restringe a ingestão de líquidos de acordo com a orientação médica ou da enfermeira?

0 - nunca $(0 \%)$

1 - quase nunca (de 1 a 2 dias ou de 1 a 13\%)

2 - poucas vezes (durante 3 a 4 dias ou de 20 a 27\%)

3 - algumas vezes (de 5 a 7 dias ou de 33 a 47\%)

4 - a maioria das vezes (de 8 a 11 dias ou de 80 a 93\%)

5- quase sempre (de 12 a 14 dias ou de 76 a $99 \%$ )

6 - sempre (durante 15 dias ou 100\%)

2.7. Você ingere frutas com alto teor de líquido, tais como laranja, melão, melancia, abacaxi, água do côco, etc.? sem considerar o líquido?

0 - sempre (durante 15 dias ou $100 \%$ )

1 - quase sempre (de 12 a 14 dias ou de 76 a 99\%)

2 - a maioria das vezes (de 8 a 11 dias ou de 80 a 93\%)

3 - algumas vezes (de 5 a 7 dias ou de 33 a 47\%)

4 - poucas vezes (durante 3 a 4 dias ou de 20 a 27\%)

5- quase nunca (de 1 a 2 dias ou de 1 a 13\%)

6 - nunca $(0 \%)$

2.8. Você ingere alguma bebida alcoólica?

0 - Sempre (durante 15 dias ou 100\%)

1 - Quase sempre (de 12 a 14 dias ou de $80 \%$ a 93\%)

2 - Freqüentemente (de 8 a 11 dias ou de $53 \%$ a $73 \%$ )

3 - Às vezes (de 5 a 7 dias ou de $33 \%$ a $47 \%$ )

4 - Poucas vezes (durante 3 ou 4 dias ou de $20 \%$ a 27\%)

5 - Quase nunca (de 1 a 2 dias ou de $7 \%$ a 13\%)

6 - Nunca (0\%)

\section{Compromissos médicos}

3.1. Você faltou alguma consulta médica, de enfermagem ou exames programados?

0 - sempre (durante 15 dias ou 100\%)

1 - quase sempre (de 12 a 14 dias ou de 76 a 99\%)

2 - a maioria das vezes (de 8 a 11 dias ou de 80 a 93\%)

3 - algumas vezes (de 5 a 7 dias ou de 33 a 47\%)

4 - poucas vezes (durante 3 a 4 dias ou de 20 a 27\%)

5 - quase nunca (de 1 a 2 dias ou de 1 a $13 \%$ )

6 - nunca $(0 \%)$ 
ANEXO 3

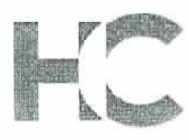

\section{CÓPIA}

\section{APROVAÇÃO}

A Comissão de Ética para Análise de Projetos de Pesquisa CAPPesa da Diretoria Clínica do Hospital das Clínicas da Faculdade de Medicina da Universidade de São Paulo, em sessão de 22/06/2011, APrOVOU O Protocolo de Pesquisa $n^{\circ}$ 0210/11, intitulado: "AUTOCUIDADO EM INSUFICIÊNCIA CARDÍACA: ESTUDO COMPARATIVO ENTRE PACIENTES DE CLÍNICA ESPECIALIZADA E PRONTO SOCORRO" apresentado pela COMISSÃO CIENTíFICA DO INCOR, inclusive O Termo de Consentimento Livre e Esclarecido.

Cabe ao pesquisador elaborar e apresentar à CAPPesq, os relatórios parciais e final sobre a pesquisa (Resolução do Conselho Nacional de Saúde $n^{\circ} 196$, de 10/10/1996, inciso IX.2, letra "c").

Pesquisador (a) Responsável: Dr. Edimar Alcides Bocchi

Pesquisador (a) Executante: Heloisa Ribeiro do Nascimento

Co-autores: Vilanice Alves de Araújo Püschel, Mucio Tavares de Oliveira Junior, Fátima das Dores Cruz.

CAPPesq, 27 de Junho de 2011

\section{WUIVISSADO CIENTIFICA \\ OM. Ot $\frac{1001}{\text { Deboo }}$}

\author{
Allites rextillos \\ PROF. DR. EUCLIDES AYRES DE CASTILHO \\ Coordenador \\ Comissão de Ética para Análise de \\ Projetos de Pesquisa - CAPPesq
}

